\title{
Contrasting interannual and multidecadal NAO variability
}

Article

Accepted Version

Woollings, T., Franzke, C., Hodson, D. L. R., Dong, B., Barnes, E. A., Raible, C. C. and Pinto, J. G. (2015) Contrasting interannual and multidecadal NAO variability. Climate Dynamics, 45 (1-2). pp. 539-556. ISSN 0930-7575 doi: https://doi.org/10.1007/s00382-014-2237-y Available at https://centaur.reading.ac.uk/37549/

It is advisable to refer to the publisher's version if you intend to cite from the work. See Guidance on citing.

Published version at: http://link.springer.com/article/10.1007/s00382-014-2237-y

To link to this article DOI: http://dx.doi.org/10.1007/s00382-014-2237-y

Publisher: Springer

Publisher statement: The final publication is available at Springer via http://dx.doi.org/10.1007/s00382-014-2237-y

All outputs in CentAUR are protected by Intellectual Property Rights law, including copyright law. Copyright and IPR is retained by the creators or other copyright holders. Terms and conditions for use of this material are defined in the End User Agreement.

www.reading.ac.uk/centaur 
Central Archive at the University of Reading

Reading's research outputs online 
Noname manuscript No.

(will be inserted by the editor)

\section{- Contrasting interannual and multidecadal NAO}

\section{variability}

${ }_{3}$ T. Woollings - C. Franzke • D. L. R.

4 Hodson - B. Dong - E. A. Barnes - C.

5 C. Raible • J. G. Pinto

6 Received: date / Accepted: date

T. Woollings

Atmospheric, Oceanic and Planetary Physics, Department of Physics, Parks Rd, Oxford,

OX1 3PU, UK E-mail: woollings@atm.ox.ac.uk

C. Franzke

Meteorologisches Institut, KlimaCampus, Universitt Hamburg, Hamburg, Germany

D. L. R. Hodson and B. Dong

NCAS-Climate and Department of Meteorology, University of Reading, Reading, UK

E. A. Barnes

Department of Atmospheric Science, Colorado State University, Fort Collins, Colorado, USA

C. C. Raible

Climate and Environmental Physics and Oeschger Centre for Climate Change Research,

University of Bern, Bern, Switzerland

J. G. Pinto

Department of Meteorology, University of Reading, Reading, UK and Institute for Geophysics and Meteorology, University of Cologne, Cologne, Germany 
7 Abstract Decadal and longer timescale variability in the winter North At-

8 lantic Oscillation (NAO) has considerable impact on regional climate, yet it 9 remains unclear what fraction of this variability is potentially predictable. This 10 study takes a new approach to this question by demonstrating clear physical 11 differences between NAO variability on interannual-decadal $(<30$ year) and 12 multidecadal ( $>30$ year) timescales. It is shown that on the shorter timescale 13 the NAO is dominated by variations in the latitude of the North Atlantic ${ }_{14}$ jet and storm track, whereas on the longer timescale it represents changes in their strength instead. NAO variability on the two timescales is associated with different dynamical behaviour in terms of eddy-mean flow interaction, 17 Rossby wave breaking and blocking. The two timescales also exhibit different 18 regional impacts on temperature and precipitation and different relationships 19 to sea surface temperatures. These results are derived from linear regression 20 analysis of the Twentieth Century and NCEP-NCAR reanalyses and of a high21 resolution HiGEM General Circulation Model control simulation, with addi22 tional analysis of a long sea level pressure reconstruction. Evidence is presented 23 for an influence of the ocean circulation on the longer timescale variability of 24 the NAO, which is particularly clear in the model data. As well as provid25 ing new evidence of potential predictability, these findings are shown to have 26 implications for the reconstruction and interpretation of long climate records.

${ }_{27}$ Keywords North Atlantic Oscillation · Jet variability · Atmosphere-ocean ${ }_{28}$ interaction $\cdot$ Climate reconstructions 
$29 \quad 1$ Introduction

30 As the leading pattern of atmospheric circulation variability over the North 31 Atlantic, the North Atlantic Oscillation ${ }^{1}$ (NAO) has a strong influence on sur32 face climate across the Atlantic basin and beyond (Thompson and Wallace 33 2001). Interest in the NAO has been partly motivated by the prominence of 34 its decadal-scale variability in winter (Stephenson et al. 2000). The increase 35 of the winter NAO index from the 1960s to the 1990s gained particular atten36 tion (Hurrell 1995) but decadal variability is also evident in longer records of 37 the NAO (Pinto and Raible 2012). In the likely absence of atmospheric mem${ }_{38}$ ory from one winter season to the next, influences from other components of 39 the climate system may have played a role. Evidence has been provided of 40 possible influences such as the extratropical (Rodwell et al. 1999; Czaja and ${ }_{41}$ Frankignoul 1999; Mosedale et al. 2006; Gastineau and Frankignoul 2012) or 42 tropical oceans (Hoerling et al. 2001; Selten et al. 2004; Greatbatch et al. 43 2012), the sea-ice (Deser et al. 2004; Bader et al. 2011) and also forcings act-

44 ing via the stratosphere, such as changes in stratospheric water vapour (Joshi

45 et al. 2006) or solar variability (Ineson et al. 2011). The associated potential

${ }_{46}$ for predictability of NAO variability continues to drive research in this area 47 (Folland et al. 2012).

${ }_{48}$ Much recent work has focused on shorter, intraseasonal timescales in at49 tempts to understand the atmospheric dynamics underlying NAO variability,

1 Or equivalently, the Arctic Oscillation or Northern Annular Mode (Feldstein and Franzke 2006). 
so following Feldstein (2003) and Benedict et al. (2004). It is clear that some of

${ }_{51}$ the NAO variability on decadal timescales could arise from so-called climate

52 noise, in which seasonal sampling of the strong intraseasonal variability can

53 lead to apparent power on interannual and longer timescales (Wunsch 1999;

${ }_{54}$ Feldstein 2000b; Schneider et al. 2003; Raible et al. 2005). Various statistical

55 methods have been applied to estimate the fraction of variance on interannual

56 and longer timescales which could be explained simply as climate noise. How-

${ }_{57}$ ever, these methods differ widely in their findings (Feldstein 2000a; Keeley

58 et al. 2009; Franzke and Woollings 2011), so that the statistical significance of

59 low-frequency NAO variability, and hence the potential for seasonal-decadal

60 predictability is still unclear. In this paper we take a different and complemen-

${ }_{61}$ tary approach, by searching for physical differences between NAO variability

62 on short and long timescales.

The NAO is essentially a description of the preferred structure of variabil-

64 ity in the North Atlantic eddy-driven jet stream (Thompson et al. 2002). This

${ }_{65}$ deep tropospheric jet represents the net effect of westerly wind forcing by the

66 transient atmospheric eddies ( $\mathrm{Li}$ and Wettstein 2012), and variations in its

67 strength and position affect regional temperatures and precipitation via vari-

${ }_{68}$ ations in the prevailing westerly winds and associated storm tracks. The NAO

69 is usually defined via patterns in surface pressure or geopotential height, using

70 methods such as principal component analysis. Physical quantities such as the

${ }_{71}$ latitude and speed of the jet are generally not separable by these methods

72 (Monahan et al. 2009), and the NAO reflects variations in both of these quan- 
73 tities (Woollings et al. 2010). When height fields are linearly regressed onto

${ }_{74}$ time series of the jet latitude and speed, both of the resulting spatial pat-

75 terns project onto the NAO pattern (Woollings and Blackburn 2012). Despite

76 this, the jet latitude and speed are clearly distinct, having different annual cy-

77 cles, power spectra and interannual variability (Woollings and Blackburn 2012;

${ }_{78}$ Woollings et al. 2014). This suggests that variations in jet latitude and speed

79 have different physical mechanisms and drivers, and yet they are combined in

so standard NAO analyses.

Here we highlight the contrasting nature of the jet variability associated with the NAO on two different timescales, namely multidecadal and interannualdecadal, with periods greater or less than 30 years respectively. This study 84 is related to other approaches which focus on the non-stationarity of the 85 NAO pattern over time (Jung et al. 2003; Lu and Greatbatch 2002; Raible et al. 2006; Wang et al. 2012; Moore et al. 2013), or multi-decadal changes 87 in regime activity (Casty et al. 2005; Franzke et al. 2011). Other studies have ${ }_{88}$ highlighted non-stationary relationships between the NAO and regional im89 pacts on temperature (Pozo-Vázquez et al. 2001; Haylock et al. 2007; Comas9o Bru and McDermott 2013), precipitation (Vicente-Serrano and López-Moreno ${ }_{91}$ 2008; Raible et al. 2014) and storm activity (Luo et al. 2011; Lee et al. 92 2012), and the timescale dependence shown here may help in interpreting 93 this non-stationarity. Finally, there is evidence for distinct patterns of ocean94 atmosphere variability on decadal/multi-decadal timescales in observations 95 and models (Deser and Blackmon 1993; Delworth and Mann 2000; Sutton and 
96 Hodson 2003; Shaffrey and Sutton 2006), with non-stationarity or frequencydependence in the relationship between the NAO and sea surface temperatures

98 (Raible et al. 2001; Walter and Graf 2002; Raible et al. 2005; Alvarez-Garcia

99 et al. 2008). Hence we also examine the NAO-SST relationship on the two

100

101

102

103

104 timescales as a preliminary study of the associated ocean-atmosphere interaction.

\section{Methods}

In this study we focus on the variability in wintertime (DJF) mean data from atmospheric reanalyses. We use both the NCEP-NCAR reanalysis (Kalnay and coauthors 1996) and the Twentieth Century reanalysis (20CR) (Compo et al. 2011). The latter uses mean sea level pressure (MSLP) observations only and takes an ensemble approach to quantify uncertainty, providing 56 estimates of atmospheric flow from 1871 to 2012 . Unless otherwise stated, the analyses presented here were performed individually for each of these ensemble members and only averaged over the ensemble at the end of the analysis.

The NCEP-NCAR reanalysis is used over the period 1950-2012. Since this only provides 62 winters of data this record is short to examine the multidecadal behaviour, but as will be shown results are qualitatively similar to those in $20 \mathrm{CR}$. This reanalysis is used particularly to investigate transient features such as the storm track and the transient eddy fluxes. These quantities have been examined in 20CR but found to give unphysical results in the low-frequency regressions, in particular at high latitudes. This is likely due 
to issues in the data-sparse period before 1920 (see e.g. Krueger et al. (2013) for a general discussion). The storm track is characterised using data filtered with a 2-6 day Chebyshev recursive filter to select only the synoptic timescales (Cappellini 1978).

We also make use of a 100 year present-day control simulation of the highresolution coupled General Circulation Model HiGEM (Shaffrey et al. 2009). This has an atmospheric resolution of $0.833^{\circ} \times 1.25^{\circ}$ in longitude-latitude with 38 levels, and an ocean resolution of $\frac{1}{3}^{\circ}$ with 40 levels. This model shows improved simulation of the climatology and variability of North Atlantic climate compared to the standard resolution HadGEM1.2 (Shaffrey et al. 2009; Keeley et al. 2012; Hodson and Sutton 2012). Some limited transient diagnostics have been derived from the HiGEM simulation and these agree well with the results from the NCEP-NCAR reanalysis.

The NAO was defined in all datasets as the leading Empirical Orthogonal Function (EOF) and associated principal component time series of monthly mean wintertime (DJF) mean sea level pressure over the Atlantic sector $\left(90^{\circ} \mathrm{W}\right.$ $\left.30^{\circ} \mathrm{E}, 30-90^{\circ} \mathrm{N}\right)$. In the $20 \mathrm{CR}$ data the $\mathrm{NAO}$ was calculated separately in each ensemble member, and the resulting average spatial pattern is shown in Figure 5a of Woollings et al. (2014, W14 hereafter). The monthly NAO index was averaged up to seasonal mean values for analysis. As described in W14, indices of jet latitude and speed were derived using the zonal wind at $850 \mathrm{hPa}$. The method essentially averages the daily zonal wind over $0-60^{\circ} \mathrm{W}$ and smoothes it using a 10-day low pass filter before locating the maximum wind speed 
(Woollings et al. 2010). The resulting daily values of jet latitude and speed were averaged over each winter season to derive seasonal mean values.

To separate the different timescales we apply Empirical Mode Decomposition (EMD), as in Franzke and Woollings (2011), to the seasonal mean time series of the NAO and jet indices. This approach empirically decomposes a time series into Intrinsic Mode Functions (IMFs) of different average periods. See Franzke and Woollings (2011) for more description and an example of the method. Here we focus on two timescales: the interannual-decadal, formed by isolating the IMFs with average periods less than 30 years, and the multidecadal, with IMF periods greater than 30 years. The sum of the two filtered time series is exactly equal to the full unfiltered series. These two timescales were chosen after experimentation to best represent the contrasting NAO behaviour (for example the 10-30 year band of timescales behave similarly to the 1-10 year band). Note that the general results presented here are reproduced using other filtering methods such as running means, but the EMD results are presented due to their smoothness and objectivity.

The general approach taken here is to linearly regress various fields onto the NAO time series at the two different timescales. After averaging the monthly data up to seasonal means, the NAO series is re-normalised so that the series of winter mean values has a mean of zero and a standard deviation of one. Maps therefore show the anomalies associated with one standard deviation of the full unfiltered winter NAO. As described below, this makes the magnitudes of the patterns on the two timescales comparable. However, it is important 
to note that the long timescale anomaly patterns then have larger amplitude than is experienced in practise.

\section{Jet Characteristics}

We begin by comparing the NAO and jet indices from 20CR in Figure 1. The decadal variability of the NAO is clear, with high NAO values dominating in the early and late twentieth century, and low NAO values dominating in the middle of the century. In contrast, the jet latitude shows mostly interannual variability, and as shown by W14 it is the jet speed which exhibits the strongest decadal variability. W14 used a Monte Carlo statistical test to assess the probability that the observed variability in the decadal means of these jet series could arise from a white noise process. The results showed that this was quite plausible for the jet latitude $(\mathrm{p}=0.19)$ but very unlikely for the jet speed $(\mathrm{p}=0.01)$

W14 also found that the jet latitude and speed series are uncorrelated $(\mathrm{r}=-$ 0.07), yet both are related to the NAO. This is shown in Figure 2 which correlates these series with the NAO series on the different timescales obtained using the EMD filtering. Both 20CR and NCEP-NCAR results are plotted, with errorbars reflecting the uncertainty across the ensemble in 20CR. On timescales shorter than 30 years the NAO is dominated by variations in jet latitude. However, on the multidecadal timescale the reverse is true for $20 \mathrm{CR}$ at least; the jet speed is more highly correlated with the NAO. NCEP-NCAR shows high correlations for both jet speed and jet latitude on this timescale. If 
the $20 \mathrm{CR}$ analysis is restricted to the time period of the NCEP-NCAR reanalysis, this gives very similar correlations to the NCEP-NCAR data (asterisks in Figure 2), suggesting that this difference is largely due to the short time period.

These correlations suggest a change in the nature of NAO variability on long timescales, with variations in jet speed becoming more important. This impression is confirmed in Figure 3 which shows the $850 \mathrm{hPa}$ zonal wind anomalies associated with NAO variability on the two timescales. On the shorter timescale the wind anomalies generally straddle the mean jet, indicating a meridional shift, although the anomalies exhibit weaker meridional tilt and are focused downstream of the mean wind maximum. On the multidecadal timescale, however, the anomalies overlie the mean jet, indicating a clear increase in jet speed during positive NAO variations. The increase in speed is also shifted towards the eastern end of the jet, highlighting an extension of the jet towards central Europe. Similar patterns are seen in the NCEP-NCAR data, despite the difference in correlation on the long timescale in Figure 2. Although the multidecadal anomalies are weaker in NCEP-NCAR, the zonal wind is strengthened along the jet core as seen in 20CR. The same behaviour is also seen in the HiGEM model control simulation, which suggests the result is not a coincidence of the recent observed period. The similarity of the patterns across the three datasets adds considerable confidence to the result. These other datasets will be used in particular to analyse the storm activity and ocean-atmosphere interaction on the two timescales, since these 
are two aspects which have proved problematic in the analysis of the $20 \mathrm{CR}$ data.

Following the jet analyses of W14, we performed a simple statistical test of the decadal NAO variability against a white noise hypothesis. For each of the 56 ensemble members, 1000 surrogate white noise NAO time series were generated with the same standard deviation, and then decadal means were calculated from these. The surrogate series were then used to determine the likelihood of the observed level of variability in decadal means occurring from the noise. This analysis showed that the decadal NAO variability in $20 \mathrm{CR}$ is very unlikely to occur in a white noise model $(\mathrm{p}=0.01)$. We then applied multiple linear regression to express the NAO as a linear combination of the jet indices (which explained $71 \%$ of the NAO variance). This enabled us to remove the influence of jet latitude and speed in turn and recalculate the likelihood of the resulting decadal NAO variability. Removing the contribution of jet latitude variations resulted in an NAO series which was still very unlikely in the noise model $(\mathrm{p}=0.01)$, but removing the contribution of jet speed gave a value of $\mathrm{p}=0.19$, so that the resulting decadal $\mathrm{NAO}$ variability was no longer significantly different from that expected from white noise. This exercise shows that it is the variations in jet speed which are responsible for the elevated power of the NAO on decadal timescales.

It would clearly be beneficial to verify the contrasting NAO behaviour on the two timescales in a longer observational dataset. Several attempts have been made to reconstruct atmospheric flow fields beyond the last century using 
instrumental records, with considerable success. We have analysed the Küttel et al. (2010) reconstruction of MSLP over Europe and the eastern North Atlantic back to 1750 , which uses both terrestrial pressure and marine wind data. The result is that this dataset does not exhibit the distinct nature of multidecadal variability shown in the other datasets. Our analysis (described in section 8) suggests that this may be at least partly an artefact of an assumption of stationarity in the method used to derive the reconstruction. Given the strong agreement between the other datasets, we conclude that the reconstruction likely underestimates the timescale dependence of NAO variability.

\section{Regional Impacts}

NAO variations are of particular interest because of their strong influence on regional surface climate. These connections have obvious societal impact and are also often used to reconstruct indices of the NAO back in time. Figure 4 shows the patterns of near surface air temperature and precipitation associated with the NAO. These impacts are notably different on the two timescales, especially over Europe. On interannual timescales this analysis gives the canonical patterns of a quadrupole in temperature anomalies and a north-south dipole in precipitation. On the decadal timescale, however, these patterns are shifted south, so that both temperature and precipitation anomalies are focused on western-central Europe. This southward shift is consistent with the role of the East Atlantic pattern (the second EOF) which also describes changes in jet speed and can be interpreted as acting to shift the NAO circulation pattern 
254 north and south (Woollings et al. 2010). Figure 4 also shows strong differences in Arctic climate on the two timescales, though this should be treated with caution. If the analysis is restricted to the first 100 years of the period (18711970) then the Arctic signal is greatly reduced. This suggests that this signal arises from a correlation with the recent Arctic warming trend, which may be unrelated to the NAO.

Some consideration of the variance of the NAO on the different timescales should be taken in interpreting these impacts. This applies to all of the regression maps shown in this paper. As described above, the NAO time series was normalised and then split into the two components. The variance of the full time series is 1.0, but the two components have very different variances: 0.90 for the interannual-decadal series and only 0.08 for the multidecadal series. This means that anomalies of the magnitude of those in the multidecadal regressions are never realised in practise; the units of these regressions are changes per standard deviation of the full NAO series, while the multidecadal changes are much smaller than this. Despite this, the anomalies are of considerable importance when compared to the level of variability on this timescale. Over western Europe the multidecadal NAO regression accounts for up to $50 \%$ of the variance in decadal mean zonal wind, and similarly $30 \%$ of the temperature and $60 \%$ of the precipitation variance. 


\section{Hemispheric connections}

In this section we investigate whether the NAO on the two timescales has different links to remote regions, in particular the Pacific. This is motivated by discussion over the hemispheric or regional nature of the NAO (Wallace 2000) and also by evidence that interaction between the Atlantic and Pacific sectors might be non-stationary or timescale dependent (Raible et al. 2001; Castanheira and Graf 2003; Pinto et al. 2011; Lee et al. 2012).

Figure 5 shows the MSLP associated with NAO variations on the two timescales. Despite the clear differences in jet behaviour, the MSLP patterns in the Atlantic are only subtly different, indicating that MSLP anomalies are hard to interpret in terms of jet characteristics. The most robust difference is an eastward shift of the equatorward Atlantic centre of action on the long timescale. The two reanalyses and the model are in good agreement over the structure of variability on the shorter timescale, including a weak centre of action in the eastern North Pacific. Climate models have historically overestimated the NAO teleconnection to the North Pacific (McHugh and Rogers 2005), but HiGEM appears to perform well in this regard (at least on the short timescale). On the longer timescale there is little agreement between the three datasets in the Pacific sector (though again the two reanalyses are similar if only the NCEP-NCAR period is used; not shown). This lack of agreement between datasets limits the confidence we can have in hemispheric connections on the long timescale. 
To further investigate the Atlantic-Pacific links in the observations, we analyse the storm track variability in the NCEP-NCAR reanalysis. The upper level storm track is summarised by the mean of $v^{\prime 2}$ at $200 \mathrm{hPa}$, which is regressed onto the NAO in Figure 6. In the Atlantic sector the contrast in storm track behaviour is very clear. The positive phase of the NAO is associated with a northward shift and extension of the storm track on interannual-decadal timescales, whereas it is associated with a strengthening of the storm track on multidecadal timescales. These features do extend upstream into the Pacific on both timescales. This is particularly clear on the multidecadal timescale, where a strong increase in storm activity is seen over the eastern North Pacific. This is consistent with the results of Lee et al. (2012) who found similar long term changes in the Atlantic and Pacific storm tracks over recent decades. Although weaker, the Pacific storm track signal on the shorter timescale is again consistent with the Atlantic flow, since it indicates a weakening on the southern side of the storm track. It is also consistent with studies which have noted a latitudinal shift of the Pacific storm track accompanying an Atlantic shift (Franzke et al. 2004; Strong and Magnusdottir 2008). Figure 6 also shows corresponding results from HiGEM. As in the MSLP analysis, there seems to be a Pacific-Atlantic storm track link on the shorter timescale which agrees well with that in the reanalysis. On the long timescale there is good agreement between the model and the reanalysis over the Atlantic sector, but not over the Pacific. 
To summarise, there is evidence that NAO variability on both timescales has links to the Pacific sector. This is particularly clear on the shorter timescale, where both MSLP and storm tracks show good agreement between the different datasets. In contrast, confidence in Atlantic-Pacific links on the longer timescale is limited by the large differences between the three datasets.

\section{Eddy-mean flow interaction}

In this section we present further dynamical diagnostics of the atmospheric circulation differences on the two timescales. We use the NCEP-NCAR reanalysis for this analysis because of higher confidence in its transient fields. Figure 7 shows the vertical structure of the zonal wind anomalies along a section at $30^{\circ} \mathrm{W}$. On both timescales the wind anomalies are equivalent barotropic with maxima in the upper troposphere. The differences between the two timescales seen at $850 \mathrm{hPa}$ are clearly evident in the eddy-driven jet through the depth of the troposphere, and are not just surface features. This suggests that the wind anomalies are accompanied by changes in transient eddy driving of the zonal flow, as expected from the storm track changes shown in Figure 6. Figure 7 also shows an interesting contrast in subtropical jet variability. This is opposite to the eddy-driven jet, in that the subtropical jet strengthens and weakens on the short timescale but shifts meridionally on the long timescale. Transient baroclinic eddies influence the large-scale flow via both heat and momentum fluxes. The top panels of Figure 8 show the lower tropospheric transient eddy heat fluxes $\left(v^{\prime} T^{\prime}\right)$. As in the other fields there is a clear 
change between the timescales from a largely shifting pattern of variability to a strengthening one. The transient eddy heat fluxes drive a residual overturning circulation with Coriolis torque acting to accelerate the westerly flow at the latitude of the maximum in $v^{\prime} T^{\prime}$. Figure 8 then shows that the changes in transient eddy heat fluxes act to support the zonal flow variations in each case, helping to shift the surface westerlies in the interannual-decadal variability and strengthen them in the multidecadal variability.

To summarise the effects of the transient eddy momentum fluxes, we follow Raible et al. (2010) in calculating $\mathbf{E} \cdot \mathbf{D}$ where $\mathbf{E}=\left(\left(v^{\prime 2}-u^{\prime 2}\right) / 2,-u^{\prime} v^{\prime}\right)$ is similar to the E-vector of Hoskins et al. (1983) and $\mathbf{D}=\left(U_{x}-V_{y}, V_{x}+U_{y}\right)$ is the deformation vector of the time mean flow. Here $u^{\prime}$ and $v^{\prime}$ are the 2-6 day band-pass filtered wind components and $U$ and $V$ are the wind components averaged over the relevant winter season. This diagnostic describes the exchange of kinetic energy between the eddies and the background flow (Mak and Cai 1989). Regressions of $\mathbf{E} \cdot \mathbf{D}$ on the NAO are shown in the lower panels of Figure 8. The climatology of $\mathbf{E} \cdot \mathbf{D}$ features positive values over North America, implying that eddies grow there at the expense of the background state. Over the Atlantic Ocean the climatology is negative, showing that the eddies lose kinetic energy to the background state there. The regression patterns are again very different on the two timescales. The multidecadal regression shows a strengthening of the conversion from eddy to background state kinetic energy, consistent with increased eddy driving of the stronger jet stream. On the interannual-decadal timescale the pattern is more complicated. While the 
region of maximum eddy forcing is shifted northward by the anomalies, the pattern also shows a meridional tightening of the eddy forcing over the ocean and a general strengthening downstream. The upstream part of this pattern may be related to the strengthening of the subtropical jet seen in Figure 7 .

The effect of eddy forcing on the mean flow of the NAO is increasingly described with regard to the breaking of transient Rossby waves (Benedict et al. 2004; Franzke et al. 2004; Rivière and Orlanski 2007; Martius et al. 2007; Kunz et al. 2009; Archambault et al. 2010). Here we use the index of Barnes and Hartmann (2012) which identifies wave breaking via the latitudinal overturning of vorticity contours. The index outputs the centroid of the wave breaking event, counting each event once only (with a median lifetime of events of two days) and discriminates between cyclonic and anticyclonic breaking based on the morphology of the overturning region. Regressions of the occurrence of wave breaking on the NAO are shown in Figure 9. On the interannual-decadal timescale, the positive NAO is associated with a reduction in cyclonic wave breaking on the poleward flank of the jet (to the south of Greenland) and an increase in wave breaking of both types on the equatorward flank of the jet. There is also a decrease in anticyclonic breaking in the subtropics, suggesting that this region of wave breaking shifts north along with the jet. These patterns are consistent with the picture that Rossby wave breaking acts to decelerate the westerly winds locally, so that breaking on the equatorward side pushes the jet polewards and vice versa (Gabriel and Peters 2008). 
On the multidecadal timescale the positive NAO is instead associated with increased wave breaking on both sides of the jet, which is consistent with the strengthening and extension of the jet. Such large-scale conditions are known to foster the occurrence of extreme windstorms over Western Europe (Hanley and Caballero 2012; Gómara et al. 2014). The strongest signals are increased cyclonic breaking to the north and increased anticyclonic breaking to the south, though the two types of breaking also show weaker increases on the opposite side of the jet. On both timescales the behaviour is therefore consistent with Strong and Magnusdottir (2008), in that the latitude of the breaking seems more important than its direction (e.g. the breaking on the equatorward side of the jet may be cyclonic as well as anticyclonic).

Finally in this section, we analyse the relationship between the NAO and blocking on both timescales. Blocking is a synoptic situation in which the westerly winds and storm tracks are blocked by a persistent, usually anticyclonic, flow anomaly. Blocking is itself related to wave-breaking (Pelly and Hoskins 2003; Altenhoff et al. 2008), though the requirements of spatial scale and persistence separate it from more transient wave breaking (Masato et al. 2009). Here we define blocking using the index of Scherrer et al. (2006) which is a two-dimensional extension of the classical Tibaldi and Molteni (1990) index. A blocking pattern is identified at a point if 1) the meridional $500 \mathrm{hPa}$ geopotential height gradient is reversed and 2) the flow is westerly to the north of the point, with a height gradient stronger than $10 \mathrm{~m}$ per degree of latitude. A 5-day persistence criterion is then applied at each gridpoint. 
Figure 10 shows the regressions of blocking activity on the NAO. On the interannual-decadal timescale, a positive NAO is associated with strongly reduced blocking over Greenland and the northern North Atlantic, as in Shabbar et al. (2001); Croci-Maspoli et al. (2007) and Woollings et al. (2008). This is also consistent with the reduction in cyclonic wave-breaking seen in Figure 9. The increase in blocking to the south of the jet and over western Europe is also consistent with previous studies (Davini et al. 2013). Essentially the jet shifts southward due to blocking on its northern flank and northward due to blocking on its southern flank.

On the multidecadal timescale, blocking anomalies are less strongly related to the NAO, with only very weak anomalies at high and low latitudes. The implication is that the effect of blocking is largely to shift the jet stream whereas transient wave breaking can act both to shift or strengthen the jet depending on its position. Interestingly, there is an increase in blocking at the jet exit over the British Isles, despite the strengthening of the westerly winds there under the positive NAO. This may be a consequence of the storm track changes, since a strong storm track upstream is favourable for block maintenance (Shutts 1983; Nakamura and Wallace 1993). Häkkinen et al. (2011) demonstrated multidecadal variability of Atlantic-European blocking associated with Atlantic Ocean variability. Such basin-wide variations in blocking do not appear in the analysis presented here, suggesting that the NAO is not a good description of that variability. 
7 Ocean-atmosphere interaction

${ }_{444}$ (Kucharski et al. 2006; Manganello 2008).

The distinct physical characteristics of decadal NAO variability suggest an influence external to the atmosphere. The slowly varying ocean circulation is one potential forcing and a natural candidate is the Atlantic variability described by the Atlantic Multidecadal Oscillation (Knight et al. 2005; Sutton and Dong 2012). Correlations of the low-frequency NAO and jet indices with a smoothed AMO index are given in Figure 1. The AMO index was obtained from the NOAA ESRL website and was derived as in Enfield et al. (2001), including detrending and smoothing with a 121 month smoother. Annual means are plotted in Figure 1. The correlations show that the NAO is weakly anticorrelated with the AMO and that most of this correlation likely comes from the decadal variability in jet speed, which gives a slightly higher correlation of -0.48. Another potential candidate for ocean forcing of decadal NAO variability is the slow evolution of ocean temperatures in the tropical western Pacific These potential links are investigated in Figure 11 by correlating winter mean sea surface temperatures (SSTs) with the NAO at the two timescales. The SST data comes from the HadISST dataset (Rayner et al. 2003) and the correlation uses the ensemble mean NAO from the complete period of the 20CR data. Only gridpoints where the correlation is significant at the $95 \%$ level are shown. On the short timescale the SSTs show the familiar tripole pattern of anomalies which is largely a response to NAO variability. On the longer timescale the SSTs show a more global pattern, with significant values 
outside of the Atlantic basin. The North Atlantic is generally cool, as expected from the negative correlation with the AMO, but the pattern is noisy and the large values elsewhere are hard to interpret and may not be physically related.

The tropical western Pacific does, however, show a perturbed meridional SST gradient, as found by Kucharski et al. (2006).

Taking a similar approach in correlating the SSTs with the time series of jet speed from 20CR gives a clearer pattern on the multidecadal timescale, comprising a cold subpolar gyre in the North Atlantic and warm anomalies elsewhere, largely confined to the southern hemisphere (lower panels of Figure 11). Both of these features are reminiscent of AMO behaviour, and lends support to the potential role of Atlantic Ocean circulation in influencing NAO changes on the multidecadal timescale (e.g. Omrani et al. 2014; Peings and Magnusdottir 2014). There is also indication of a potential influence from the tropical Indian Ocean as suggested by Bader and Latif (2003).

In order to provide further evidence of an ocean influence, we examine the ocean-atmosphere coupling in more detail in the HiGEM simulation, where data availability and quality is not a limiting factor. Hodson and Sutton (2012) previously investigated the North Atlantic ocean-atmosphere coupling in this model with a focus on the shorter timescale. Figure 12 shows the correlation of winter (DJF) mean SST with the long timescale NAO for the model. This shows a distinct cold North Atlantic subpolar gyre; a pattern which is at least qualitatively similar to that related to jet speed in the observations (Figure 11).

Figure 13a shows time series of the subpolar gyre temperature and the long 
timescale NAO variability, which show reasonable covariability on the long timescale.

In order to determine an influence of the ocean on the atmosphere, Figure $13 \mathrm{~b}$ presents the heat content budget for the subpolar gyre region. The sum of the heat contributions due to individual fluxes is shown by the dotted black line, and this agrees well with the total heat content in the thick black line, showing that all terms have been accounted for. The budget shows that it is the ocean heat flux convergence (in red) which is driving the heat content changes of the subpolar gyre, with the atmospheric fluxes (latent, sensible heating) acting to damp the changes in heat content. This agrees with the observational study of Gulev et al. (2013) which shows that ocean-atmosphere surface heat fluxes are driven by the ocean on multidecadal timescales.

The variations in ocean heat flux convergence into the subpolar gyre may be driven by a number of factors. Figure 13c demonstrates that these variations are closely related to variations in the Meridional Overturning Circulation at $45^{\circ} \mathrm{N}$, suggesting that variations in meridional ocean transport are responsible. These variations in turn arise in response to west to east ocean pressure gradient across the Atlantic basin, which is dominated by ocean density variations on the deep western Atlantic boundary (Figure 13c: green line). The resulting picture is that the decadal variations in the SST of the subpolar gyre (see Figure 13a) are driven by changes in the MOC in the model, which are in turn driven by variations in the density within the deep western boundary current. Such density variations are ultimately generated at the ocean surface 
in small regions of intense ocean cooling, such as the Labrador Sea (Marshall and Schott 1999). NAO variability is thought to be a significant factor in driving variations in ocean cooling in these regions (Eden and Willebrand 2001). Density anomalies generated by this process then slowly propagate southwards along the western Atlantic boundary.

In summary, subpolar SST anomalies in HiGEM arise due to changes in ocean heat convergence. These subpolar SST anomalies then in turn influence the atmosphere, likely by changing the meridional temperature gradient and hence the baroclinicity across the storm track. With a cold subpolar gyre the meridional gradient is strengthened which is expected to lead to stronger storm activity as seen in Figures 6 and 8. This in turn leads to increased acceleration of the westerly flow (Figure 8) and a stronger jet. Evidence of this mechanism of ocean influence on the atmosphere has been found in the natural variabilty of other models (Gastineau and Frankignoul 2012), in the context of model biases (Keeley et al. 2012) and in the response of models to climate change Woollings et al. 2012).

\section{Implications for long climate reconstructions}

In this section we analyse the Küttel et al. (2010) reconstruction of Atlantic/European MSLP back to 1750 for evidence of contrasting NAO behaviour on the short and long timescales. The NAO in the reconstructed data is defined as the first EOF of winter mean MSLP over the region $\left(0-40^{\circ} \mathrm{W}, 20-70^{\circ} \mathrm{N}\right)$, which roughly comprises the North Atlantic portion of the data domain. The surface 
geostrophic zonal wind $u_{g}$ is then derived from the MSLP and this is regressed onto the NAO at the two different timescales. The results are shown in the top panels of Figure 14. In contrast to the other datasets, the differences between the two regression patterns are small, with the NAO largely describing a jet shift on both timescales. To test whether this is due to the use of $u_{g}$ rather than $u_{850}$, we apply the same procedure to derive $u_{g}$ from $20 \mathrm{CR}$ and the results are shown in the middle panels of Figure 14 . The results for 20CR resemble the difference in $u_{850}$ found between a jet shift on short timescales and an increase in speed on longer timescales (Figure 3), suggesting that $u_{g}$ from the reconstruction should be capable of capturing this behaviour.

The reconstruction method used in Küttel et al. (2010) is the multivariate principal component regression technique which relies on the assumption of stationarity. EOFs of both observed MSLP fields and pressure-sensitive proxy data (e.g., early measurements and documentary data such as ship log books) are combined with a multiple linear regression technique for the observational period to project local proxy information onto regional patterns. The linear relation is then assumed to be stationary over time and used to reconstruct MSLP fields further back in time. It is possible that the similarity of the NAO regressions on the two timescales is a consequence of this assumption of stationarity. To investigate this possibility we have performed a simple test on the $20 \mathrm{CR}$ data, treating it in an analogous way to the reconstruction method.

Firstly an EOF analysis of the MSLP is performed on the last 30 years of the 20CR data. Only the first four EOFs are retained, which explain $91 \%$ of 
the variance of this sample. These EOFs are then used as a basis to truncate the full 136 year dataset: a multiple linear regression technique considering the anomaly maps for each year, the four leading EOFs and the associated principal component time series are used to derive MSLP fields by only including the projection on these four EOFs. The resulting pseudo-reconstructed MSLP fields are then regressed on the NAO at the two timescales and finally $u_{g}$ is calculated from these. The results, shown in the lower panels of Figure 14, indicate some differences between the two timescales but these are substantially weaker than those in the original 20CR analysis (middle panels of Figure 14). This is particularly clear over Europe where the latitude of the wind anomalies is quite different in the middle panels but not in the lower panels. Retaining more than four EOFs (e.g. 10 EOFs which comprises $99 \%$ of the variance) does not significantly alter these findings (not shown). While this procedure is analogous but not identical to the technique of Küttel et al. (2010), it does suggest that the lack of a distinct multidecadal NAO signature in the reconstruction could be at least partly due to the assumption of stationarity in the method. This effect could be compounded by the relatively low density of proxy data in the jet stream region over the ocean considered in the reconstruction of Küttel et al. (2010), and non-climatic noise intrinsic to proxy data.

\section{Conclusions}

This study shows that the multidecadal variability of the NAO represents very different variations in atmospheric circulation from the interannual-decadal 
variability. The faster variability is dominated by meridional shifts of the jet

stream and associated storm track, while the slower variability is dominated by changes in the speed of the jet and the strength of the storm track.

Variations on both timescales are supported by forcing from the transient eddies, but the nature of this forcing is different. The interannual-decadal variations are associated with shifts of the transient eddy forcing and with the occurrence of blocking weather patterns. Other work suggests this variability represents variations in the occurrence of different synoptic circulation regimes such as preferred jet positions (W14 and references therein). In contrast, the multidecadal variability is associated with changes in strength of the eddy forcing and with in-phase changes in the occurrence of transient Rossby wave breaking on both sides of the jet.

The patterns of influence of the $\mathrm{NAO}$ on regional temperatures, wind speeds and precipitation are different on the two timescales, and this has clear implications for the interpretation of proxy or reconstructed records of past atmospheric variability in this region. The variations on multidecadal timescales may not be well represented by the canonical NAO pattern, especially since the shorter timescale variability dominates the variance of the NAO index. A potential example of this has been given, by analysing a long MSLP reconstruction. In contrast to the other datasets, this does not exhibit a difference in NAO character on short and long timescales, and it is suggested that the stationarity assumption commonly used in reconstruction methods is at least 
partly responsible for this. These findings have implications for the interpre-

tation of climate reconstructions and long climate records.

These results also provide strong evidence for the presence of some forcing on the decadal NAO from more slowing varying components of the climate system than the atmosphere. Some evidence of links to Atlantic Ocean variability were revealed, although other factors may also contribute. This evidence is particularly clear in the HiGEM GCM, where variations in the Atlantic Meridional Overturning Circulation lead to significant SST anomalies in the subpolar gyre region which are then damped by the heat fluxes to the atmosphere.

For the emerging discipline of decadal prediction these results are an encouraging sign of potential predictability of the winter NAO on multidecadal timescales. Furthermore, the multidecadal component of NAO variability has a clear and distinct influence on surface temperatures and precipitation, especially in Europe, so that decadal forecasts of this variability could be of practical use. However, the contrasting behaviour on interannual and decadal timescales suggests that the potential sources of skill may be different for decadal forecasts than for seasonal forecasts.

Acknowledgements. NCEP Reanalysis data provided by the NOAA/OAR/ESRL PSD, Boulder, Colorado, USA, from their Web site at http://www.esrl.noaa.gov/psd/. Support for the Twentieth Century Reanalysis Project dataset is provided by the U.S. Department of Energy, Office of Science Innovative and Novel Computational Impact on Theory and Experiment (DOE INCITE) program, and 
Office of Biological and Environmental Research (BER), and by the National Oceanic and Atmospheric Administration Climate Program Office. CF is supported by the German Research Foundation through the cluster of excellence CliSAP. DLRH was supported by the National Centre for Atmospheric Science (NCAS) and the Natural Environmental Research Council (NERC) during this work. CCR is supported by the Swiss National Science Foundation under the grant CRSI122-130642 (FUPSOL). JGP was partially supported by the German Federal Ministry of Education and Research (BMBF) under the project Probabilistic Decadal Forecast for Central and western Europe (MIKLIP-PRODEF, contract 01LP1120A). The authors would like to thank Len Shaffrey and the HiGEM project http://higem.nerc.ac.uk/ for use of the HiGEM data in this study, and two anonymous reviewers for constructive comments.

\section{References}

Altenhoff, A. M., Martius, O., Croci-Maspoli, M., Schwierz, C., and Davies, H. C. (2008). Linkage of atmospheric blocks and synoptic-scale rossby waves: a climatological analysis. Tellus A, 60(5), 1053-1063.

Alvarez-Garcia, F., Latif, M., and Biastoch, A. (2008). On multidecadal and quasi-decadal North Atlantic variability. J. Climate, 21(14), 3433-3452.

Archambault, H. M., Keyser, D., and Bosart, L. F. (2010). Relationships between large-scale regime transitions and major cool-season precipitation 
events in the northeastern United States. Mon. Weather Rev., 138(9), 34543473.

Bader, J. and Latif, M. (2003). The impact of decadal-scale indian ocean sea surface temperature anomalies on sahelian rainfall and the north atlantic oscillation. Geophys. Res. Lett., 30, 2169.

Bader, J., Mesquita, M. D., Hodges, K. I., Keenlyside, N., Østerhus, S., and Miles, M. (2011). A review on Northern Hemisphere sea-ice, storminess and the North Atlantic Oscillation: Observations and projected changes. Atmospheric Research, 101(4), 809-834.

Barnes, E. A. and Hartmann, D. L. (2012). Detection of Rossby wave breaking and its response to shifts of the midlatitude jet with climate change. $J$ Geophys. Res., 117(D09117).

Benedict, J. J., Lee, S., and Feldstein, S. B. (2004). Synoptic view of the North Atlantic Oscillation. J. Atmos. Sci., 61(2), 121-144.

Cappellini, V. (1978). Digital filters and their applications. Academic Press. 393 pp.

Castanheira, J. and Graf, H.-F. (2003). North Pacific-North Atlantic relationships under stratospheric control? J. Geophys. Res., 108, 4036.

Casty, C., Handorf, D., Raible, C., González-Rouco, J., Weisheimer, A., Xoplaki, E., Luterbacher, J., Dethloff, K., and Wanner, H. (2005). Recurrent climate winter regimes in reconstructed and modelled $500 \mathrm{hPa}$ geopotential height fields over the North Atlantic/European sector 1659-1990. Climate Dynam., 24(7-8), 809-822. 
Comas-Bru, L. and McDermott, F. (2013). Impacts of the EA and SCA patterns on the European twentieth century NAO-winter climate relationship. Q. J. R. Meteorol. Soc. doi: 10.1002/qj.2158.

Compo, G. P., Whitaker, J. S., Sardeshmukh, P. D., Matsui, N., Allan, R. J., Yin, X., Gleason, B. E., Vose, R. S., Rutledge, G., Bessemoulin, P., Brönnimann, S., Brunet, M., Crouthamel, R. I., Grant, A. N., Groisman, P. Y., Jones, P. D., Kruk, M. C., Kruger, A. C., Marshall, G. J., Maugeri, M., Mok, H. Y., Nordli, Ø., Ross, T. F., Trigo, R. M., Wang, X. L., Woodruff, S. D., and Worley, S. J. (2011). The Twentieth Century Reanalysis Project. Q. J. R. Meteorol. Soc., 137, 1-28.

Croci-Maspoli, M., Schwierz, C., and Davies, H. (2007). Atmospheric blocking - Space-time links to the NAO and PNA. Climate Dynam., 29, 713-725.

Czaja, A. and Frankignoul, C. (1999). Influence of the North Atlantic SST on the atmospheric circulation. Geophys. Res. Lett., 26(19), 2969-2972.

Davini, P., Cagnazzo, C., Fogli, P. G., Manzini, E., Gualdi, S., and Navarra, A. (2013). European blocking and Atlantic jet stream variability in the NCEP/NCAR reanalysis and the CMCC-CMS climate model. Climate Dynam. doi:10.1007/s00382-013-1873-y.

Delworth, T. L. and Mann, M. E. (2000). Observed and simulated multidecadal variability in the northern hemisphere. Climate Dynam., 16(9), 661-676.

Deser, C. and Blackmon, M. L. (1993). Surface climate variations over the North Atlantic Ocean during winter: 1900-1989. J. Climate, 6(9), 17431753. 
Deser, C., Magnusdottir, G., Saravanan, R., and Phillips, A. (2004). The effects of North Atlantic SST and sea ice anomalies on the winter circulation in CCM3. Part II: Direct and indirect components of the response. J. Climate, 17, 877-889.

Eden, C. and Willebrand, J. (2001). Mechanism of interannual to decadal variability of the North Atlantic circulation. J. Climate, 14(10), 2266-2280.

Enfield, D. B., Mestas-Nuñez, A. M., and Trimble, P. J. (2001). The Atlantic Multidecadal Oscillation and its relation to rainfall and river flows in the continental US. Geophys. Res. Lett., 28(10), 2077-2080.

Feldstein, S. B. (2000a). Is interannual zonal mean flow variability simply climate noise? Journal of climate, 13(13), 2356-2362.

Feldstein, S. B. (2000b). The timescale, power spectra, and climate noise properties of teleconnection patterns. J. Climate, 13, 4430-4440.

Feldstein, S. B. (2003). The dynamics of NAO teleconnection pattern growth and decay. Q. J. R. Meteorol. Soc., 129(589), 901-924.

Feldstein, S. B. and Franzke, C. (2006). Are the North Atlantic Oscillation and the Northern Annular Mode distinguishable? J. Atmos. Sci., 63, 2915-2930.

Folland, C., Scaife, A., Lindesay, J., and Stephenson, D. (2012). How potentially predictable is northern European winter climate a season ahead? International Journal of Climatology, 32(6), 801-818.

Franzke, C. and Woollings, T. (2011). On the persistence and predictability properties of North Atlantic climate variability. J. Climate, 24, 466-472. 
Franzke, C., Lee, S., and Feldstein, S. B. (2004). Is the North Atlantic Oscillation a breaking wave? J. Atmos. Sci., 61(2), 145-160.

Franzke, C., Woollings, T., and Martius, O. (2011). Persistent circulation regimes and preferred regime transitions in the North Atlantic. J. Atmos. Sci., 68, 2809-2825.

Gabriel, A. and Peters, D. (2008). A diagnostic study of different types of Rossby wave breaking events in the northern extratropics. Journal of the Meteorological Society of Japan, 86(5), 613-631.

Gastineau, G. and Frankignoul, C. (2012). Cold-season atmospheric response to the natural variability of the Atlantic meridional overturning circulation. Climate Dynam., 39, 37-57. 10.1007/s00382-011-1109-y.

Gómara, I., Pinto, J. G., Woollings, T., Masato, G., Zurita-Gotor, P., and Rodríguez-Fonseca, B. (2014). Rossby Wave-Breaking analysis of explosive cyclones in the Euro-Atlantic sector. Q. J. R. Meteorol. Soc., 140, 738-753. doi:10.1002/qj.2190.

Greatbatch, R. J., Gollan, G., Jung, T., and Kunz, T. (2012). Factors influencing northern hemisphere winter mean atmospheric circulation anomalies during the period 1960/61 to 2001/02. Q. J. R. Meteorol. Soc., 138(669), 1970-1982.

Gulev, S. K., Latif, M., Keenlyside, N., Park, W., and Koltermann, K. P. (2013). North Atlantic Ocean control on surface heat flux on multidecadal timescales. Nature, 499(7459), 464-467. 
Häkkinen, S., Rhines, P. B., and Worthen, D. L. (2011). Atmospheric blocking and Atlantic multidecadal ocean variability. Science, 334, 655-659.

Hanley, J. and Caballero, R. (2012). The role of large-scale atmospheric flow and Rossby wave breaking in the evolution of extreme windstorms over Europe. Geophys. Res. Lett., 39(21), L21708.

Haylock, M., Jones, P., Allan, R., and Ansell, T. (2007). Decadal changes in 1870-2004 northern hemisphere winter sea level pressure variability and its relationship with surface temperature. J. Geophys. Res., 112(D11), D11103.

Hodson, D. L. and Sutton, R. T. (2012). The impact of resolution on the adjustment and decadal variability of the Atlantic meridional overturning circulation in a coupled climate model. Climate Dynam., 39(12), 3057-3073.

Hoerling, M. P., Hurrell, J. W., and Xu, T. (2001). Tropical origins for recent North Atlantic climate change. Science, 292, 90-92.

Hoskins, B. J., James, I. N., and White, G. H. (1983). The shape, propagation and mean-flow interaction of large-scale weather systems. J. Atmos. Sci., 40, 1595-1612.

Hurrell, J. W. (1995). Decadal trends in the North Atlantic Oscillation: Regional temperatures and precipitation. Science, 269, 676-679.

Ineson, S., Scaife, A. A., Knight, J. R., Manners, J. C., Dunstone, N. J., Gray, L. J., and Haigh, J. D. (2011). Solar forcing of winter climate variability in the northern hemisphere. Nature Geoscience, 4(11), 753-757.

Joshi, M. M., Charlton, A. J., and Scaife, A. A. (2006). On the influence of stratospheric water vapor changes on the tropospheric circulation. Geophys. 
Res. Lett., 33, L09806.

Jung, T., Hilmer, M., Ruprecht, E., Kleppek, S., Gulev, S. K., and Zolina, O. (2003). Characteristics of the recent eastward shift of interannual NAO variability. J. Climate, 16(20), 3371-3382.

Kalnay, E. and coauthors (1996). The NCEP/NCAR 40-year reanalysis project. Bull. Amer. Meteor. Soc., 77, 437-471.

Keeley, S., Sutton, R., and Shaffrey, L. (2012). The impact of North Atlantic sea surface temperature errors on the simulation of North Atlantic European region climate. Q. J. R. Meteorol. Soc., 138(668), 1774-1783.

Keeley, S. P. E., Sutton, R., and Shaffrey, L. (2009). Does the North Atlantic Oscillation show unusual persistence on intraseasonal timescales? Geophys. Res. Lett., 36, L22706.

Knight, J. R., Allan, R. J., Folland, C. K., Vellinga, M., and Mann, M. E. (2005). A signature of persistent natural thermohaline circulation cycles in observed climate. Geophys. Res. Lett., 32, L20708.

Krueger, O., Schenk, F., Feser, F., and Weisse, R. (2013). Inconsistencies between long-term trends in storminess derived from the 20CR reanalysis and observations. J. Climate, 26(3), 868-874.

Kucharski, F., Molteni, F., and Bracco, A. (2006). Decadal interactions between the western Tropical Pacific and the North Atlantic Oscillation. Climate Dynam., 26, 79-91.

Kunz, T., Fraedrich, K., and Lunkeit, F. (2009). Impact of synoptic-scale wave breaking on the NAO and its connection with the stratosphere in ERA-40. 
J. Climate, 22(20), 5464-5480.

Küttel, M., Xoplaki, E., Gallego, D., Luterbacher, J., Garcia-Herrera, R., Allan, R., Barriendos, M., Jones, P., Wheeler, D., and Wanner, H. (2010). The importance of ship log data: reconstructing North Atlantic, European and Mediterranean sea level pressure fields back to 1750. Climate Dynam., 34(7-8), 1115-1128.

Lee, S.-S., Lee, J.-Y., Wang, B., Ha, K.-J., Heo, K.-Y., Jin, F.-F., Straus, D. M., and Shukla, J. (2012). Interdecadal changes in the storm track activity over the North Pacific and North Atlantic. Climate Dynam., 39(1-2), 313-327.

Li, C. and Wettstein, J. J. (2012). Thermally driven and eddy-driven jet variability in reanalysis. J. Climate, 25(5), 1587-1596.

Lu, J. and Greatbatch, R. J. (2002). The changing relationship between the NAO and northern hemisphere climate variability. Geophys. Res. Lett., $\mathbf{2 9}(7), 52-1-52-4$

Luo, D., Diao, Y., and Feldstein, S. B. (2011). The variability of the Atlantic storm track and the North Atlantic Oscillation: A link between intraseasonal and interannual variability. J. Atmos. Sci., 68(3), 577-601.

Mak, M. and Cai, M. (1989). Local barotropic instability. J. Atmos. Sci., 46(21), 3289-3311.

Manganello, J. V. (2008). The influence of sea surface temperature anomalies on low-frequency variability of the North Atlantic Oscillation. Climate Dynam., 30(6), 621-641. 
Marshall, J. and Schott, F. (1999). Open-ocean convection: Observations, theory, and models. Reviews of Geophysics, 37(1), 1-64.

Martius, O., Schwierz, C., and Davies, H. C. (2007). Breaking waves at the tropopause in the wintertime Northern Hemisphere: Climatological analyses of the orientation and the theoretical LC1/2 classification. J. Atmos. Sci., 64, 2576-2592.

Masato, G., Hoskins, B. J., and Woollings, T. J. (2009). Can the frequency of blocking be described by a red noise process? J. Atmos. Sci., 66, 2143-2149.

McHugh, M. J. and Rogers, J. C. (2005). Multi-model representation of the North Atlantic Oscillation in the 20th and 21st centuries. Geophys. Res. Lett., 32, L21713.

Monahan, A. H., Fyfe, J. C., Ambaum, M. H. P., Stephenson, D. B., and North, G. R. (2009). Empirical Orthogonal Functions: The medium is the message. J. Climate, 22, 6501-6514.

Moore, G. W. K., Renfrew, I. A., and Pickart, R. S. (2013). Multidecadal mobility of the North Atlantic Oscillation. J. Climate, 26, 2453-2466.

Mosedale, T. J., Stephenson, D. B., Collins, M., and Mills, T. C. (2006). Granger causality of coupled climate processes: Ocean feedback on the North Atlantic Oscillation. J. Climate, 19(7), 1182-1194.

Nakamura, H. and Wallace, J. M. (1993). Synoptic behavior of baroclinic eddies during the blocking onset. Mon. Weather Rev., 121, 1892-1903.

Omrani, N.-E., Keenlyside, N. S., Bader, J., and Manzini, E. (2014). Stratosphere key for wintertime atmospheric response to warm Atlantic decadal 
conditions. Climate Dynam., 42(3-4), 649-663.

Peings, Y. and Magnusdottir, G. (2014). Forcing of the wintertime atmospheric circulation by the multidecadal fluctuations of the North Atlantic ocean. Environmental Research Letters, 9(3), 034018.

Pelly, J. L. and Hoskins, B. J. (2003). A new perspective on blocking. J. Atmos. Sci., 60, 743-755.

Pinto, J. G. and Raible, C. C. (2012). Past and recent changes in the North Atlantic Oscillation. WIREs Clim Change, 3, 79-90.

Pinto, J. G., Reyers, M., and Ulbrich, U. (2011). The variable link between PNA and NAO in observations and in multi-century CGCM simulations. Climate Dynam., 36(1-2), 337-354.

Pozo-Vázquez, D., Esteban-Parra, M., Rodrigo, F., and Castro-Diez, Y. (2001). A study of NAO variability and its possible non-linear influences on European surface temperature. Climate Dynam., 17(9), 701-715.

Raible, C., Luksch, U., Fraedrich, K., and Voss, R. (2001). North Atlantic decadal regimes in a coupled GCM simulation. Climate Dynam., 18(3-4), $321-330$.

Raible, C. C., Stocker, T. F., Yoshimori, M., Renold, M., Beyerle, U., Casty, C., and Luterbacher, J. (2005). Northern hemispheric trends of pressure indices and atmospheric circulation patterns in observations, reconstructions, and coupled GCM simulations. J. Climate, 18, 3968-3982.

Raible, C. C., Casty, C., Luterbacher, J., Pauling, A., Esper, J., Frank, D. C., Büntgen, U., Roesch, A. C., Tschuck, P., Wild, M., et al. (2006). Cli- 
mate variability-observations, reconstructions, and model simulations for the Atlantic-European and Alpine region from 1500-2100 AD. Climatic Change, 79(1-2), 9-29.

Raible, C. C., Ziv, B., Saaroni, H., and Wild, M. (2010). Winter synoptic-scale variability over the Mediterranean Basin under future climate conditions as simulated by the ECHAM5. Climate Dynam., 35(2-3), 473-488.

Raible, C. C., Lehner, F., Rouco, J. F. G., and Donado, L. F. (2014). Changing correlation structures of the Northern Hemisphere atmospheric circulation from 1000 to 2100 AD. Clim. Past., 10, 537-550. ".

Rayner, N. A., Parker, D. E., Horton, E. B., Folland, C. K., Alexander, L. V., Rowell, D. P., Kent, E. C., and Kaplan, A. (2003). Global analyses of sea surface temperature, sea ice, and night marine air temperature since the late nineteenth century. J. Geophys. Res., 10(D14), 4407.

Rivière, G. and Orlanski, I. (2007). Characteristics of the Atlantic storm-track eddy activity and its relation with the North Atlantic Oscillation. Journal of Atmospheric Sciences, 64, 241-266.

Rodwell, M. J., Rowell, D. P., and Folland, C. K. (1999). Oceanic forcing of the wintertime North Atlantic Oscillation and European climate. Nature, 398, 320-323.

Scherrer, S. C., Croci-Maspoli, M., Schwierz, C., and Appenzeller, C. (2006). Two-dimensional indices of atmospheric blocking and their statistical relationship with winter climate patterns in the Euro-Atlantic region. International Journal of Climatology, 26, 233-249. 
Schneider, E. K., Bengtsson, L., and Hu, Z.-Z. (2003). Forcing of northern hemisphere climate trends. Journal of the atmospheric sciences, $\mathbf{6 0}(12)$, $1504-1521$.

Selten, F. M., Branstator, G. W., Dijkstra, H. A., and Kliphuis, M. (2004). Tropical origins for recent and future Northern Hemisphere climate change. Geophys. Res. Lett., 31, L21205.

Shabbar, A., Huang, J., and Higuchi, K. (2001). The relationship between the wintertime North Atlantic Oscillation and blocking episodes in the North Atlantic. International Journal of Climatology, 21, 355-369.

Shaffrey, L. and Sutton, R. (2006). Bjerknes compensation and the decadal variability of the energy transports in a coupled climate model. J. Climate, 19, 1167-1181.

Shaffrey, L. C. et al. (2009). U.K. HiGEM: The new U.K. High-resolution Global Environment Model - Model description and basic evaluation. $J$. Climate, 22, 1861-1896.

Shutts, G. J. (1983). The propagation of eddies in diffluent jet streams: Eddy vorticity forcing of blocking flow fields. Q. J. R. Meteorol. Soc., 109, 737761.

Stephenson, D. B., Pavan, V., and Bojariu, R. (2000). Is the North Atlantic Oscillation a random walk? International Journal of Climatology, 20, 1-18. Strong, C. and Magnusdottir, G. (2008). How Rossby wave breaking over the Pacific forces the North Atlantic Oscillation. Geophys. Res. Lett., 35(10), L10706. 
Strong, C. and Magnusdottir, G. (2008). Tropospheric Rossby wave breaking and the NAO/NAM. Journal of Atmospheric Sciences, 65, 2861-2876.

Sutton, R. and Hodson, D. (2003). Influence of the ocean on North Atlantic climate variability 1871-1999. J. Climate, 16(20), 3296-3313.

Sutton, R. T. and Dong, B. (2012). Atlantic Ocean influence on a shift in European climate in the 1990s. Nature Geosci., 5(11), 788-792.

Thompson, D. W. J. and Wallace, J. M. (2001). Regional climate impacts of the Northern Hemisphere Annular Mode. Science, 293, 85-89.

Thompson, D. W. J., Lee, S., and Baldwin, M. P. (2002). Atmospheric processes governing the Northern Hemisphere Annular Mode / North Atlantic Oscillation. In J. W. Hurrell, Y. Kushnir, G. Ottersen, and M. Visbeck, editors, The North Atlantic Oscillation: Climatic Significance and Environmental Impact, volume 134. AGU Geophysical Monograph Series.

Tibaldi, S. and Molteni, F. (1990). On the operational predictability of blocking. Tellus, 42A, 343-365.

Vicente-Serrano, S. M. and López-Moreno, J. I. (2008). Nonstationary influence of the North Atlantic Oscillation on European precipitation. $J$. Geophys. Res., 113(D20), D20120.

Wallace, J. M. (2000). North Atlantic Oscillation/Annular Mode: Two paradigms - one phenomenon. Q. J. R. Meteorol. Soc., 126(564), 791-805. Walter, K. and Graf, H.-F. (2002). On the changing nature of the regional connection between the North Atlantic Oscillation and sea surface temperature. J. Geophys. Res., 107(D17), 4338. 
Wang, Y.-H., Magnusdottir, G., Stern, H., Tian, X., and Yu, Y. (2012). Decadal variability of the NAO: Introducing an augmented NAO index. Geophys. Res. Lett., 39(21), L21702.

Woollings, T. and Blackburn, M. (2012). The North Atlantic jet stream under climate change, as described by the NAO and EA patterns. J. Climate, 25, 886-902.

Woollings, T., Hannachi, A., and Hoskins, B. (2010). Variability of the North Atlantic eddy-driven jet stream. Q. J. R. Meteorol. Soc., 649, $856-868$.

Woollings, T., Gregory, J. M., Pinto, J. G., Reyers, M., and Brayshaw, D. J. (2012). Response of the North Atlantic storm track to climate change shaped by ocean-atmosphere coupling. Nature Geosci., 5, 313-317.

Woollings, T., Czuchnicki, C., and Franzke, C. (2014). Twentieth century North Atlantic jet variability. Q. J. R. Meteorol. Soc., 140, 783-791. doi: 10.1002/qj.2197.

Woollings, T. J., Hoskins, B. J., Blackburn, M., and Berrisford, P. (2008). A new Rossby wave-breaking interpretation of the North Atlantic Oscillation. J. Atmos. Sci., 65, 609-626.

Wunsch, C. (1999). The interpretation of short climate records, with comments on the North Atlantic and Southern Oscillations. Bull. Amer. Meteor. Soc., 80(2), 245-255. 

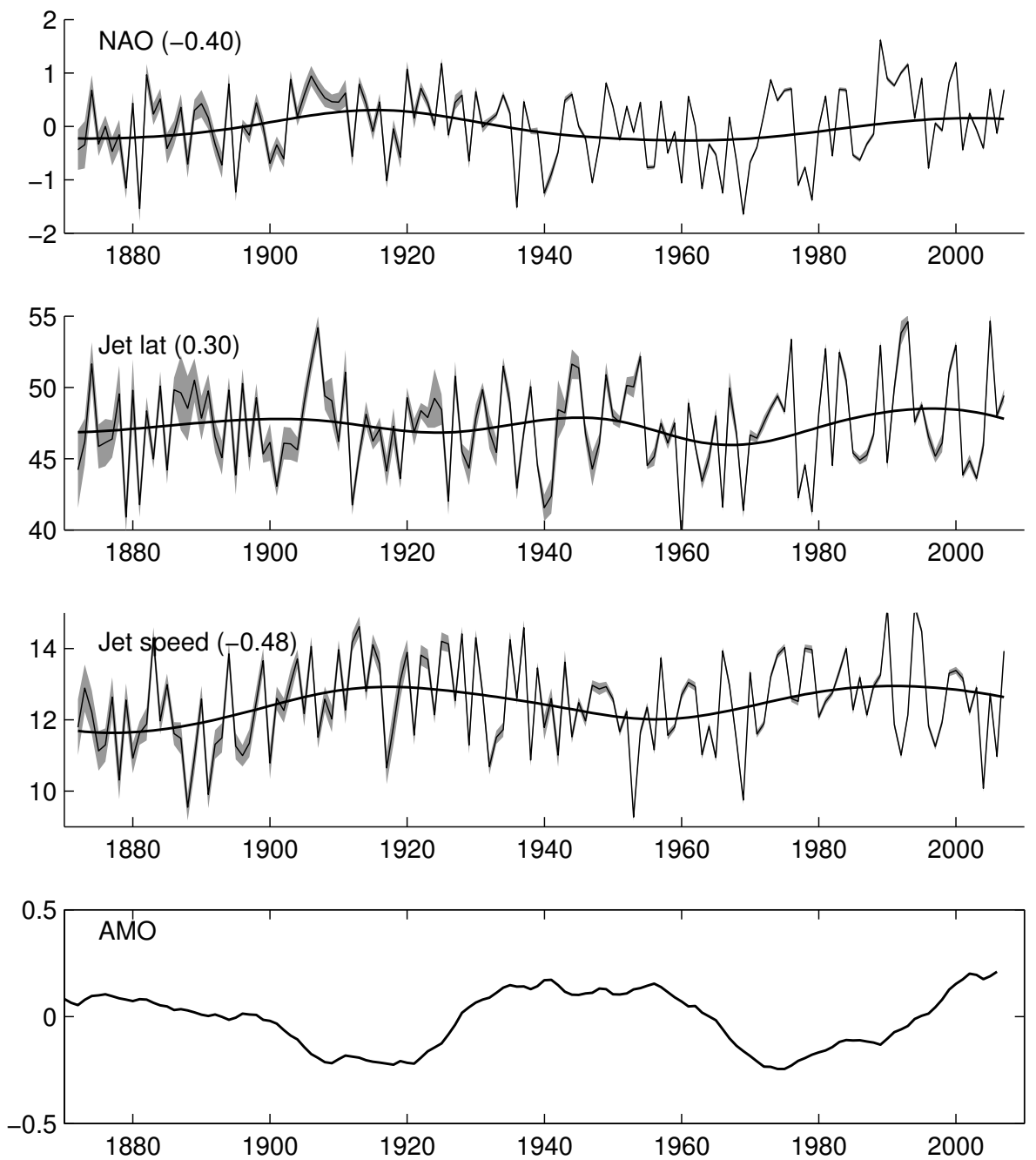

Fig. 1 Ensemble mean indices of the winter mean NAO, jet latitude and jet speed from 20CR, with the multidecadal (>30 year) component also shown. The shading indicates the \pm 2 standard deviation range across the ensemble. The AMO is shown in the bottom panel, and in each other panel the correlation of the respective low-frequency timescale with this is given. 


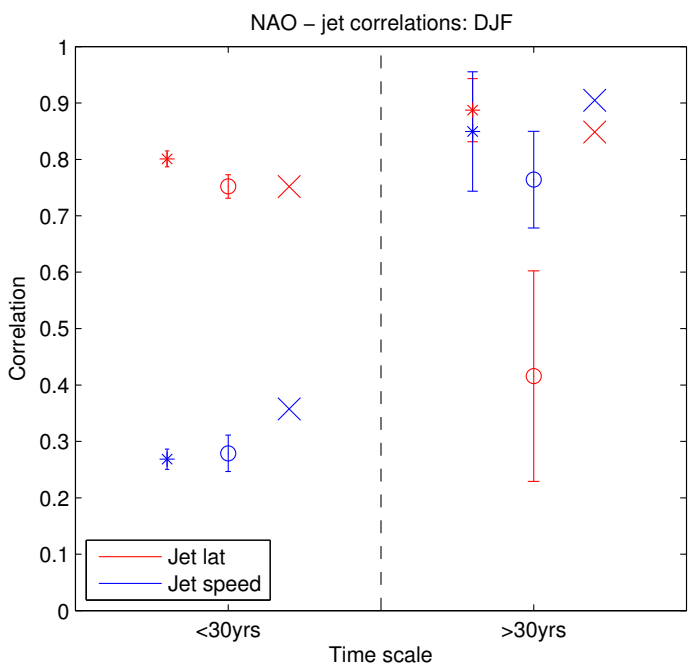

Fig. 2 Correlations of jet indices with the NAO on short and long timescales, showing NCEP-NCAR results as crosses and $20 \mathrm{CR}$ as circles, with errorbars giving the \pm 2 standard deviation range across the ensemble. Asterisks give $20 \mathrm{CR}$ results for the NCEP-NCAR period. 


\section{U850 regressed on NAO}
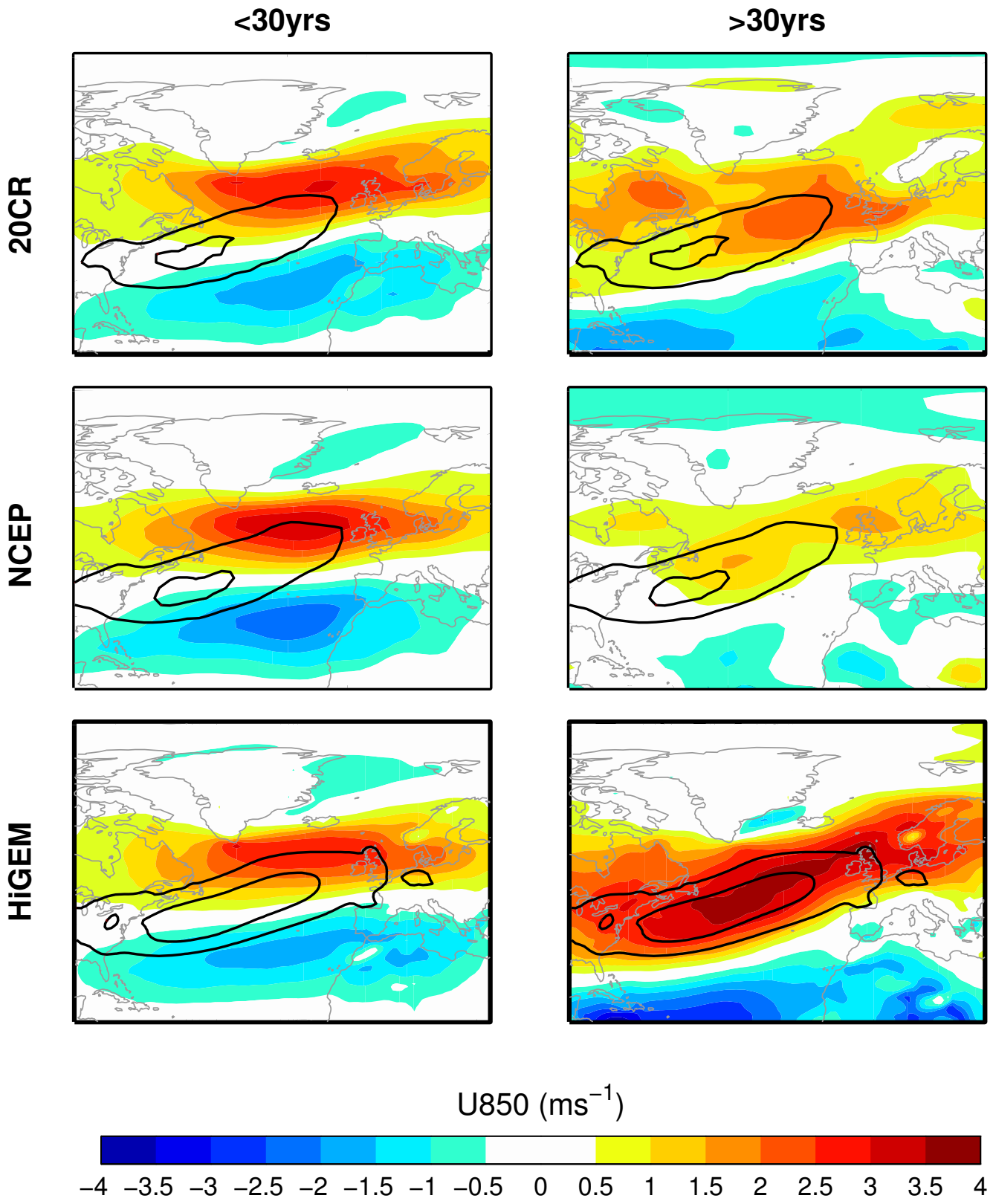

Fig. 3 Regression patterns of anomalies in $850 \mathrm{hPa}$ zonal wind on the NAO at the two timescales, using 20CR, NCEP-NCAR and HiGEM. The wind climatology is shown in black contours at 7.5 and $10.5 \mathrm{~ms}^{-1}$ 


\section{Surface air temperature regressed on NAO}
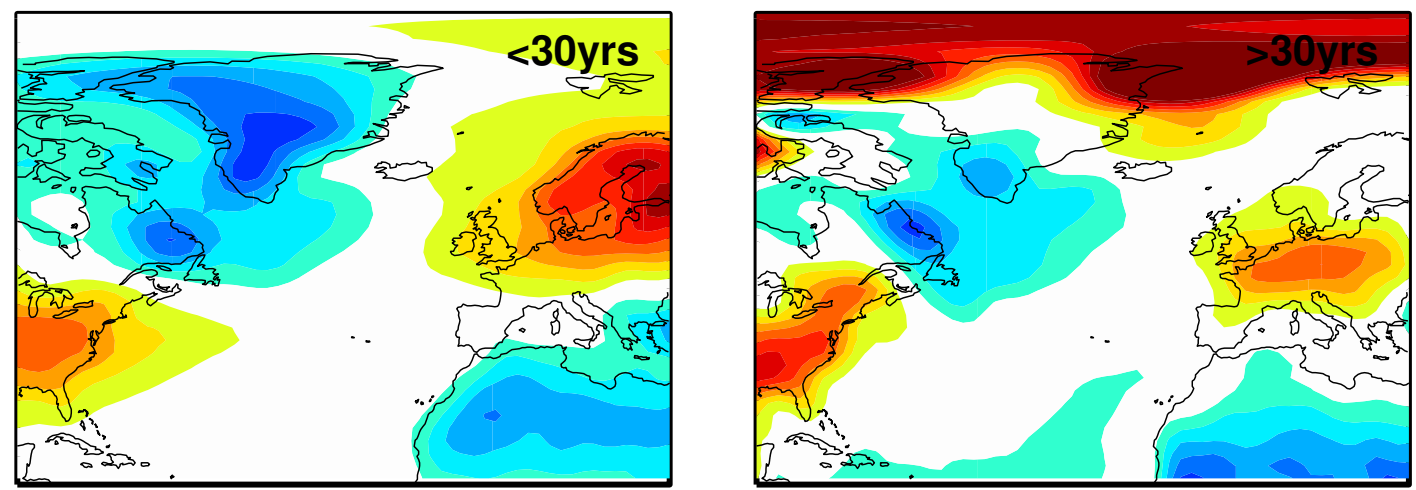

Temp (K) on sigma=0.995

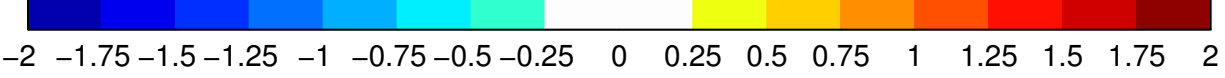

\section{Precipitation regressed on NAO}
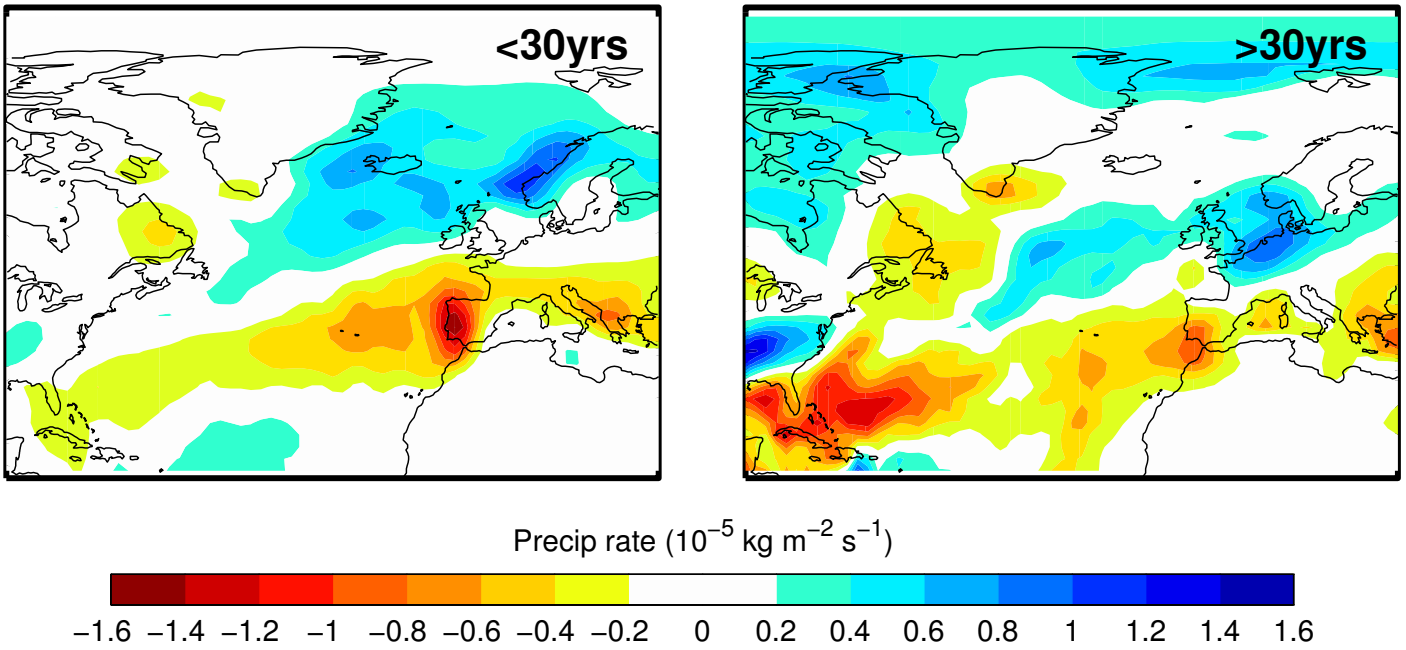

Fig. 4 Regression patterns of near surface air temperature (on the $\sigma=0.995$ level) and precipitation on the NAO at the two timescales. This analysis was performed on the ensemble mean fields from 20CR. 


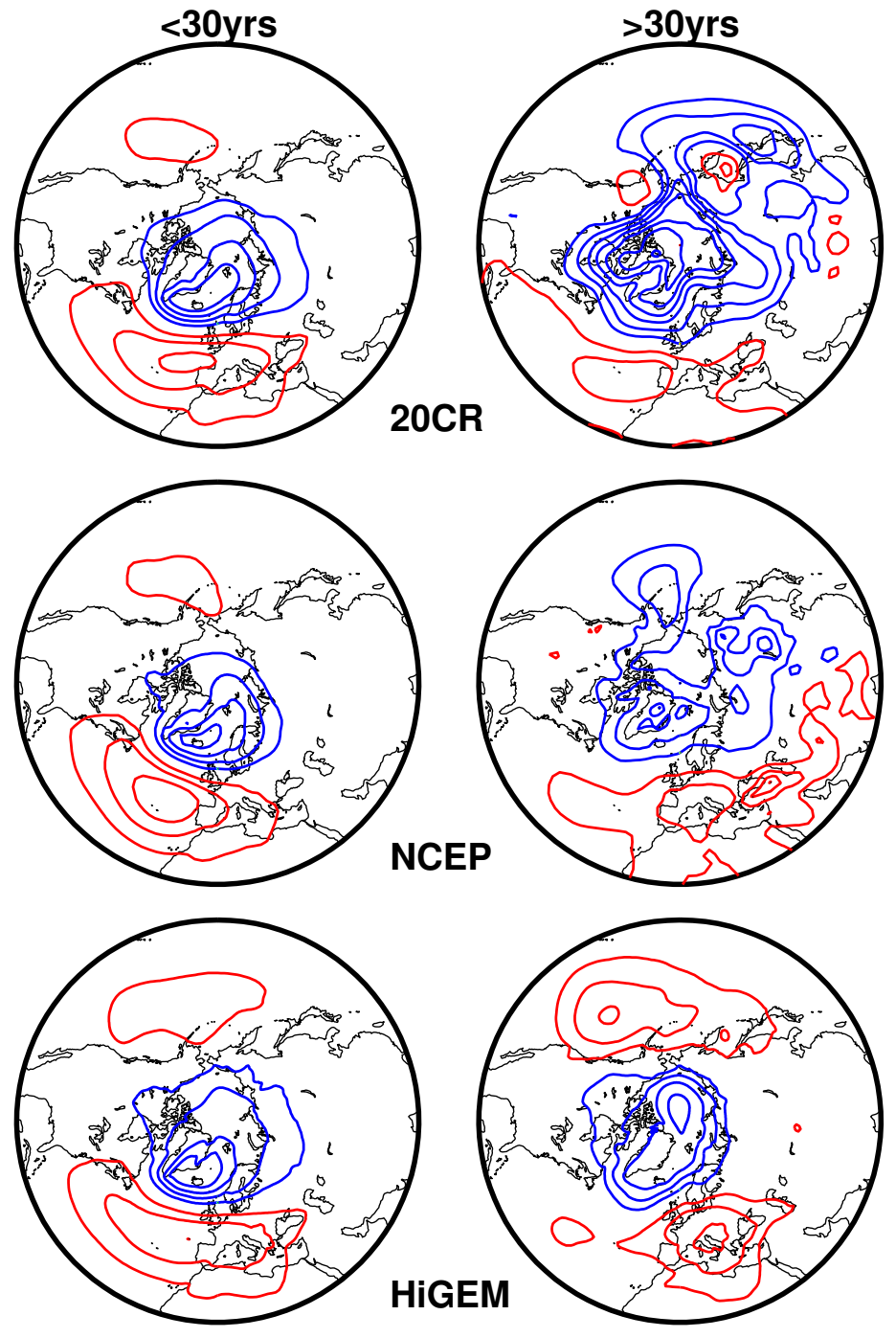

Fig. 5 MSLP from both reanalyses and from the HiGEM model regressed onto the NAO on both timescales. Contours are drawn every $1 \mathrm{hPa}$ with negative contours in blue. All ensemble members are used for $20 \mathrm{CR}$ and the results averaged. 


\section{Storm track regressed on NAO (NCEP)}
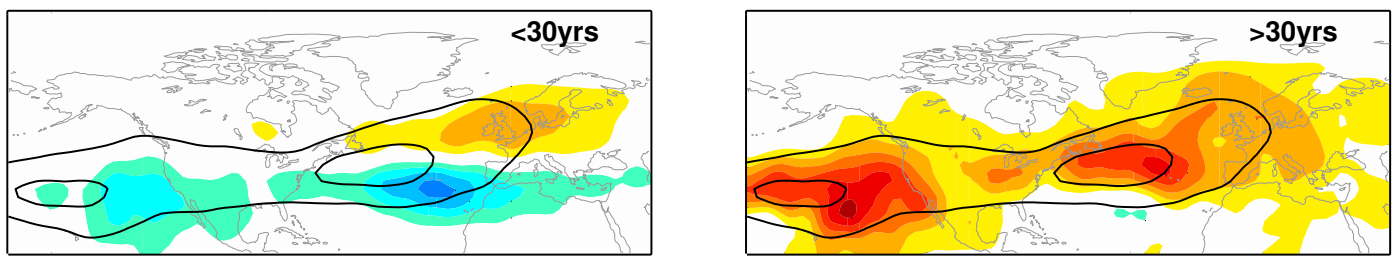

Storm track regressed on NAO (HiGEM)
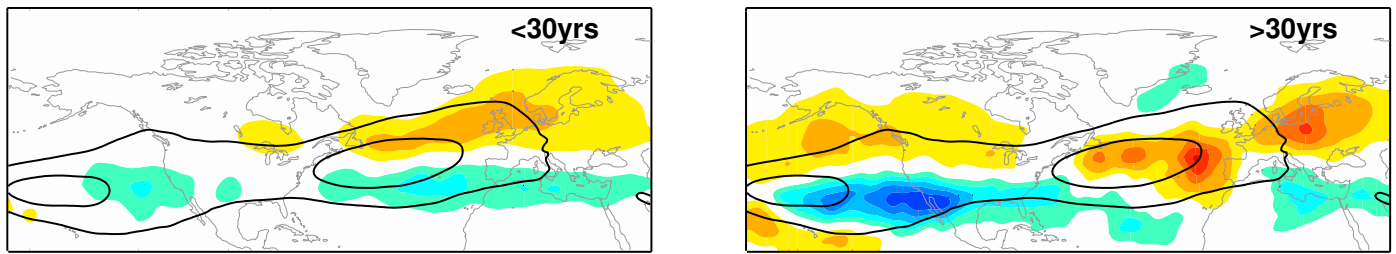

High-pass 200hPa $v^{2}\left(\mathrm{~m}^{2} \mathrm{~s}^{-2}\right)$

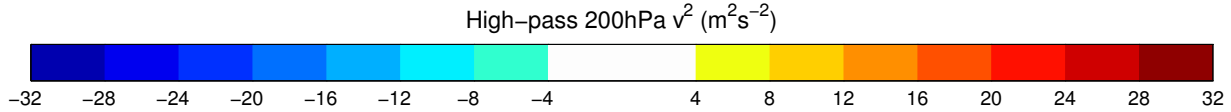

Fig. 6 Regressions of the storm track activity on the NAO in the NCEP-NCAR reanalysis and HiGEM, using the square of the meridional wind anomalies after applying a 2-6 day filter. The climatology is contoured at 60 and $100 \mathrm{~m}^{2} \mathrm{~s}^{-2}$. 


\section{$\mathrm{U}(30 \mathrm{~W})$ regressed on NAO (NCEP)}
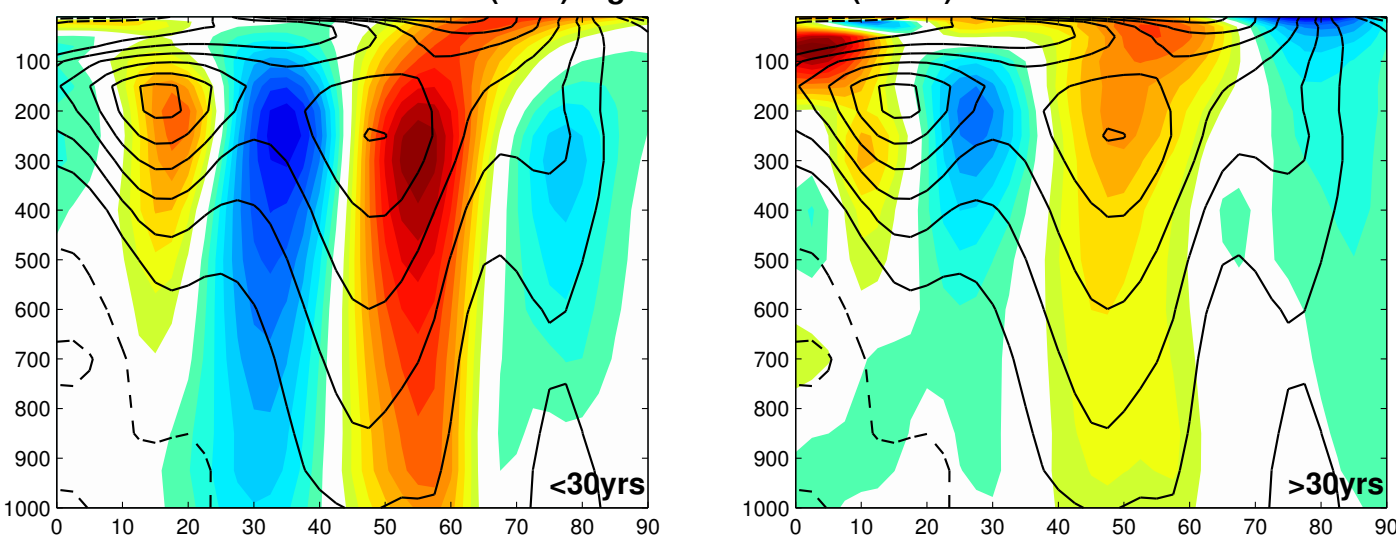

Zonal wind $\left(\mathrm{ms}^{-1}\right)$

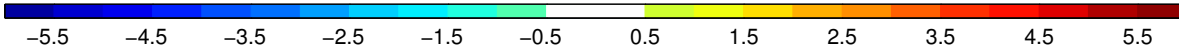

Fig. 7 Regression patterns of anomalies in zonal wind at $30^{\circ} \mathrm{W}$ on the NAO at the interannual and decadal timescales, using the NCEP reanalysis. The wind climatology is contoured every $5 \mathrm{~ms}^{-1}$. 
High-pass vT850 regressed on NAO
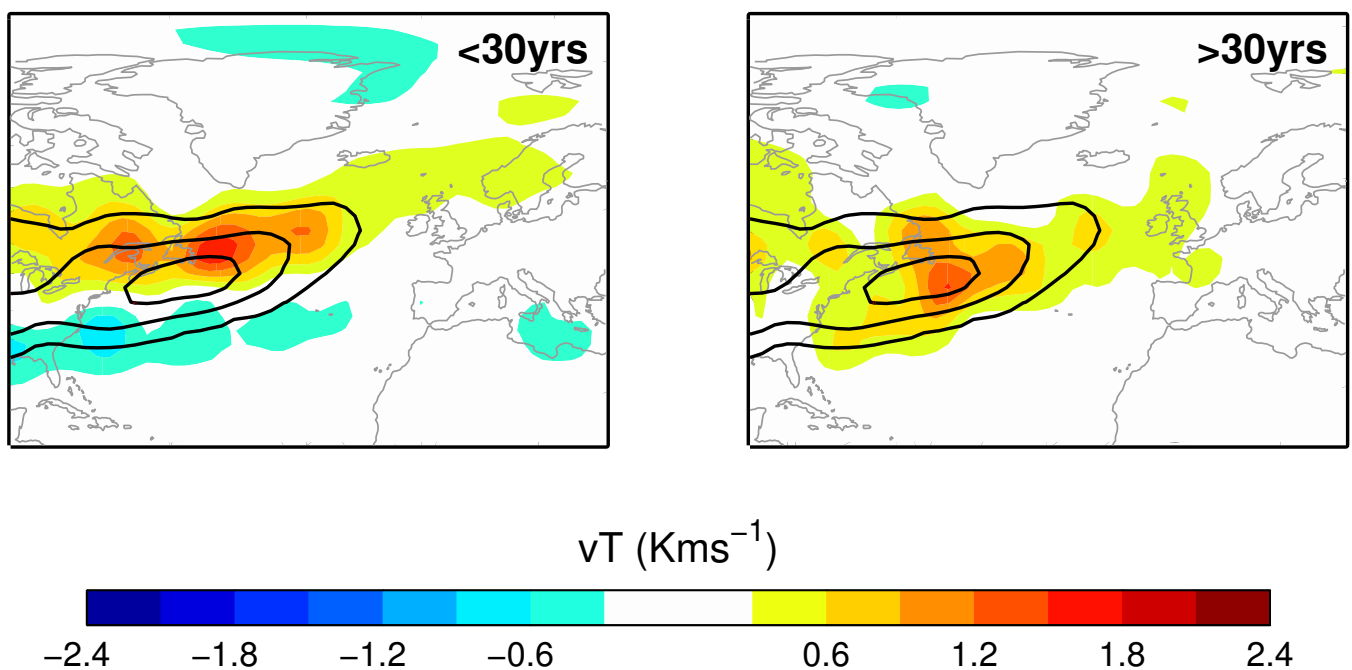

2-6 day eddy forcing regressed on NAO
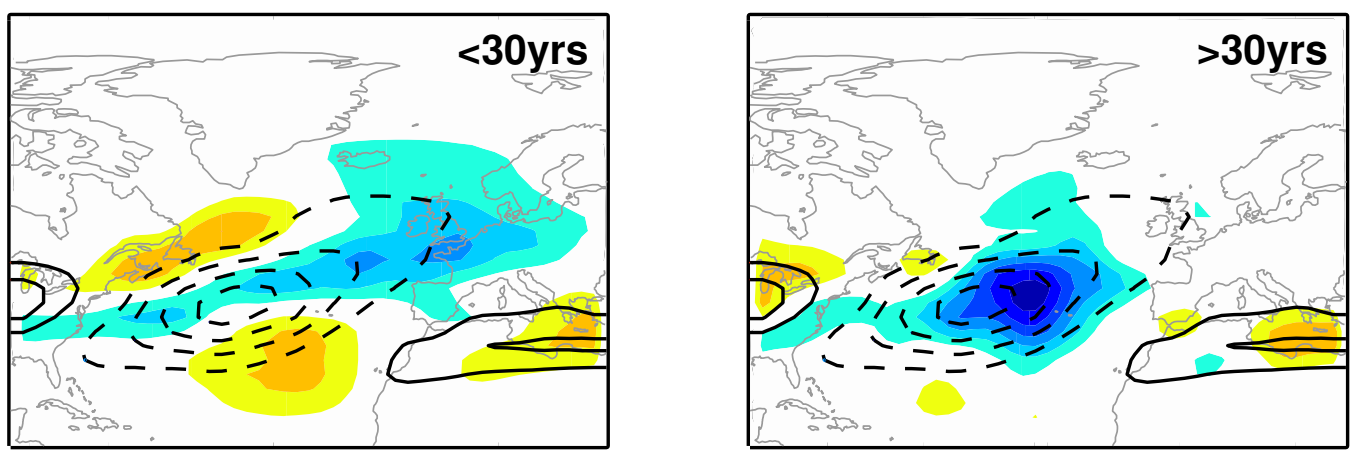

$E \cdot D\left(m^{2} s^{-3}\right)$

$\begin{array}{lllllllllllllll}-3.5 & -3 & -2.5 & -2 & -1.5 & -1 & -0.5 & 0 & 0.5 & 1 & 1.5 & 2 & 2.5 & 3 & 3.5 \\ & & & & & & & & & & & 10^{-4}\end{array}$

Fig. 8 Top: Regressions on the NAO of the 2-6 day v'T' at $850 \mathrm{hPa}$. The climatology is contoured at 4, 7 and $10 \mathrm{Km} \mathrm{s}^{-1}$. Bottom: Regressions on the NAO of the eddy forcing diagnostic $\mathbf{E} \cdot \mathbf{D}$ at $250 \mathrm{hPa}$. The climatology is contoured every $5 \mathrm{~m}^{2} \mathrm{~s}^{-3}$, with negative contours dashed and the zero contour omitted. In all cases the data is from the NCEPNCAR reanalysis. 

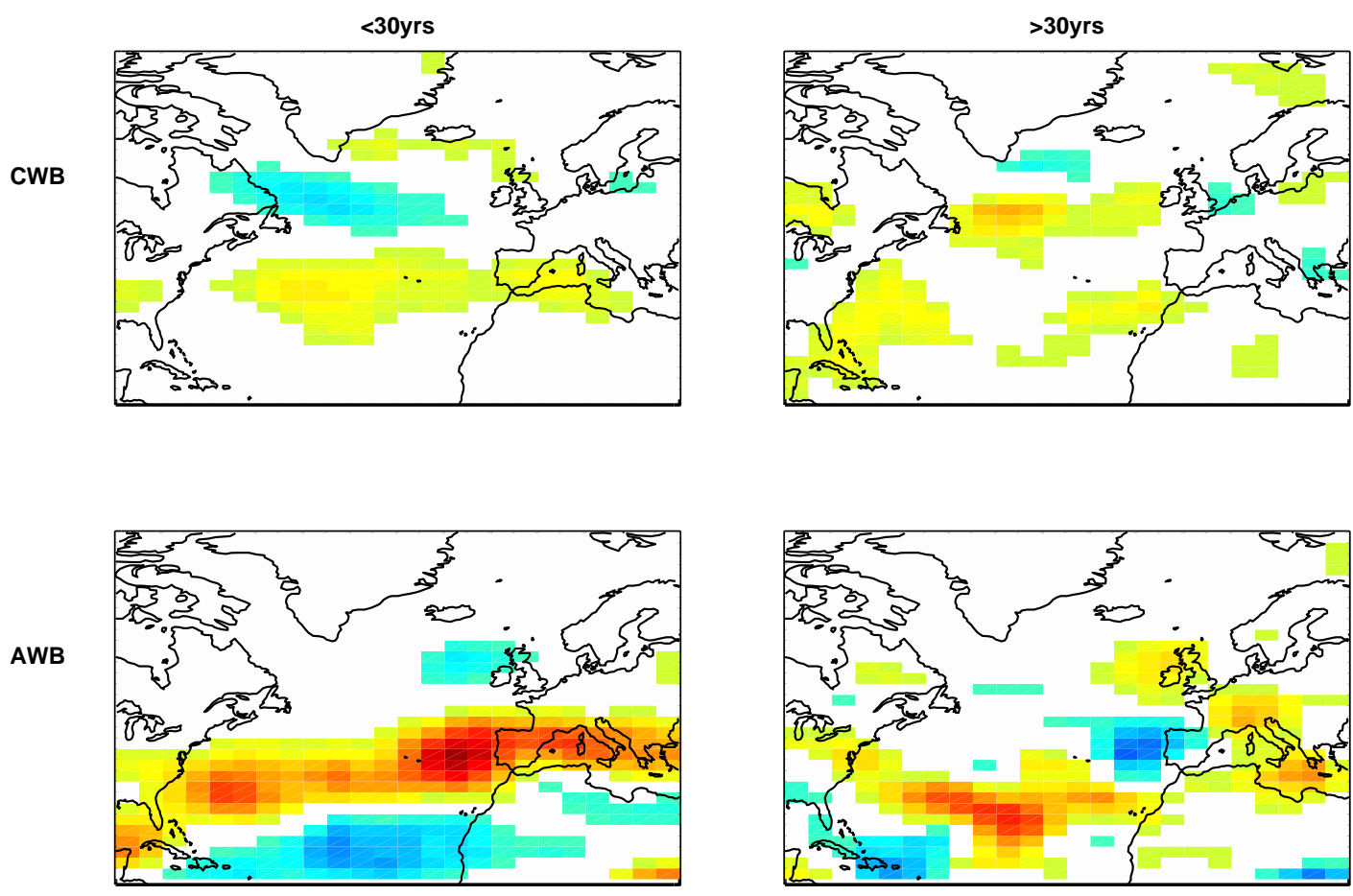

RWB freq (per 2 deg lat/lon)

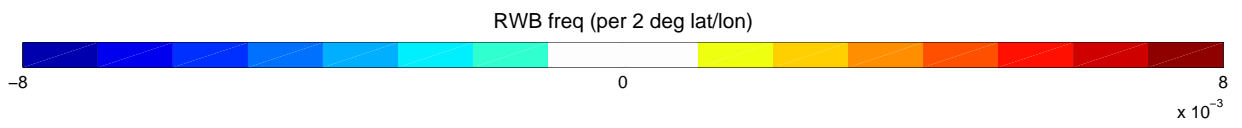

Fig. 9 Regressions on the NAO of the transient Rossby wave breaking occurrence, split into cyclonic (CWB) and anticyclonic (AWB). The NCEP-NCAR reanalysis is used. 


\section{Blocking regressed on NAO}
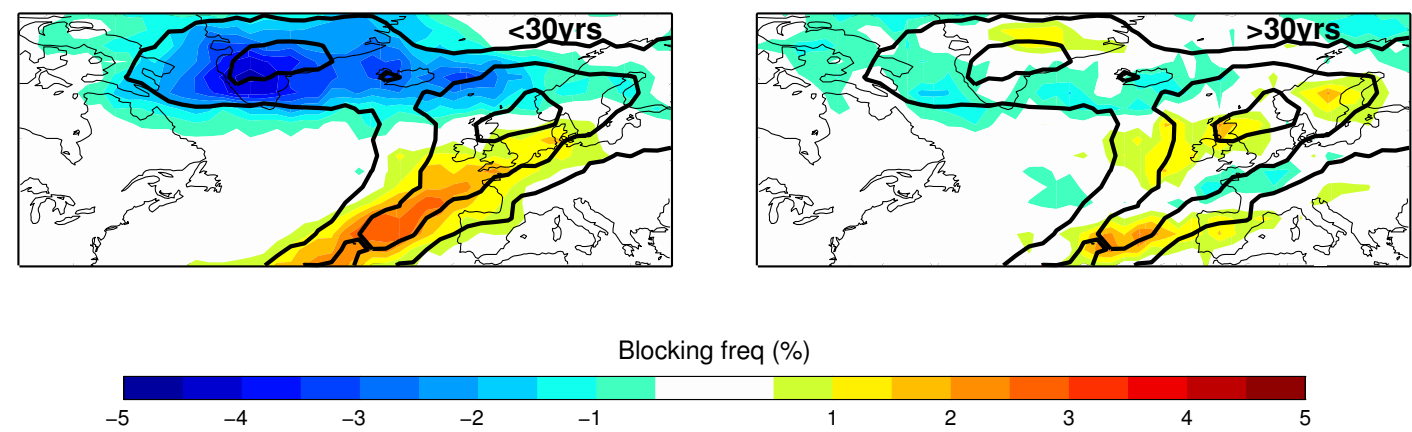

Fig. 10 Regressions of blocking occurrence on the NAO, using the NCEP-NCAR reanalysis.

The climatology is shown in black contours every $2 \%$. 

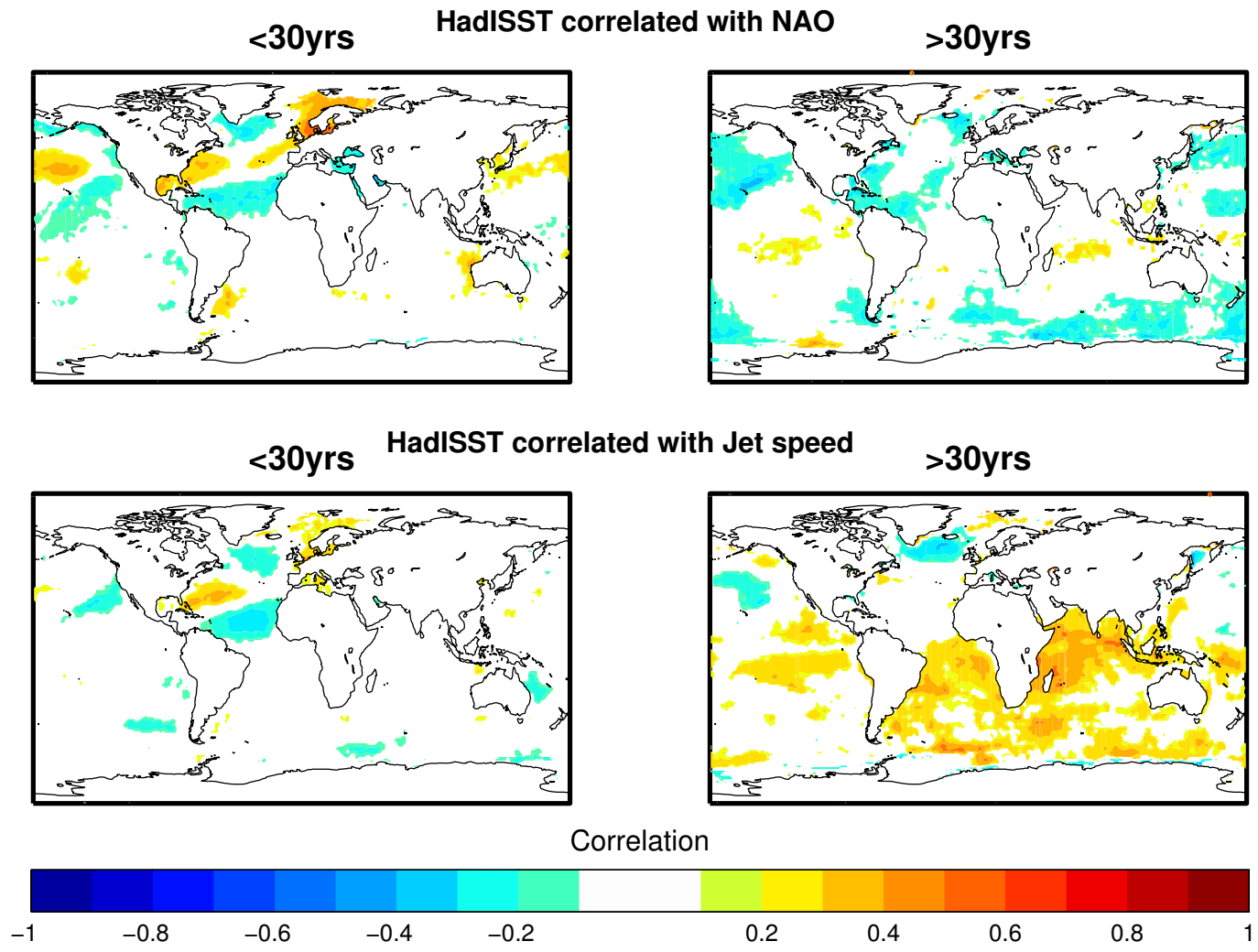

Fig. 11 Correlation value $\mathrm{r}$ of winter mean SSTs on the NAO (top) and jet speed (bottom) at the two timescales. Only values which are significant at the $95 \%$ level have been plotted. 


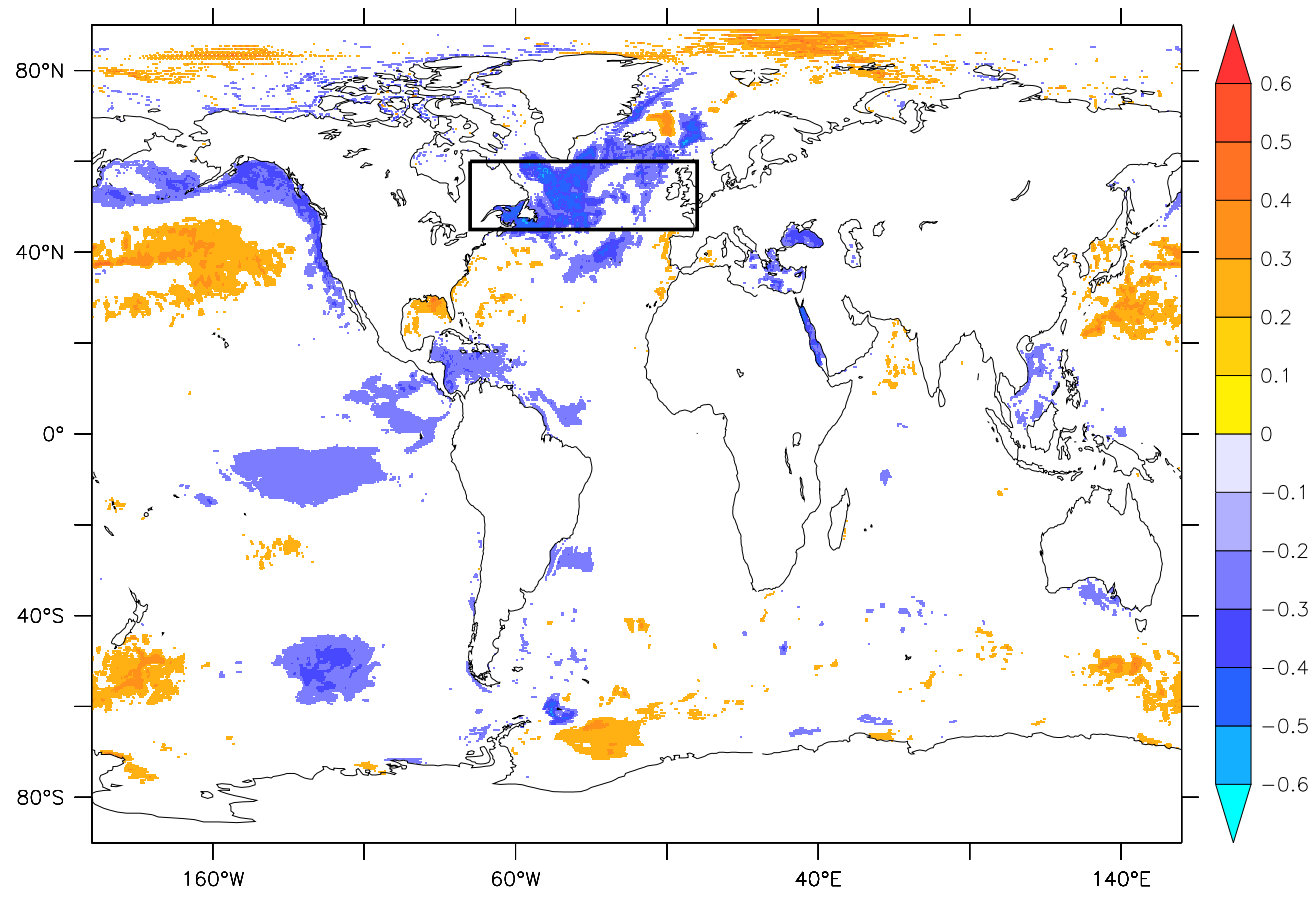

Fig. 12 Correlation value $\mathrm{r}$ of Sea Surface Temperature (SST) correlated with multidecadal NAO index in HiGEM. Shaded areas are significant at the 95\% level $(p<0.05)$. Both SST and NAO were detrended before correlation. 

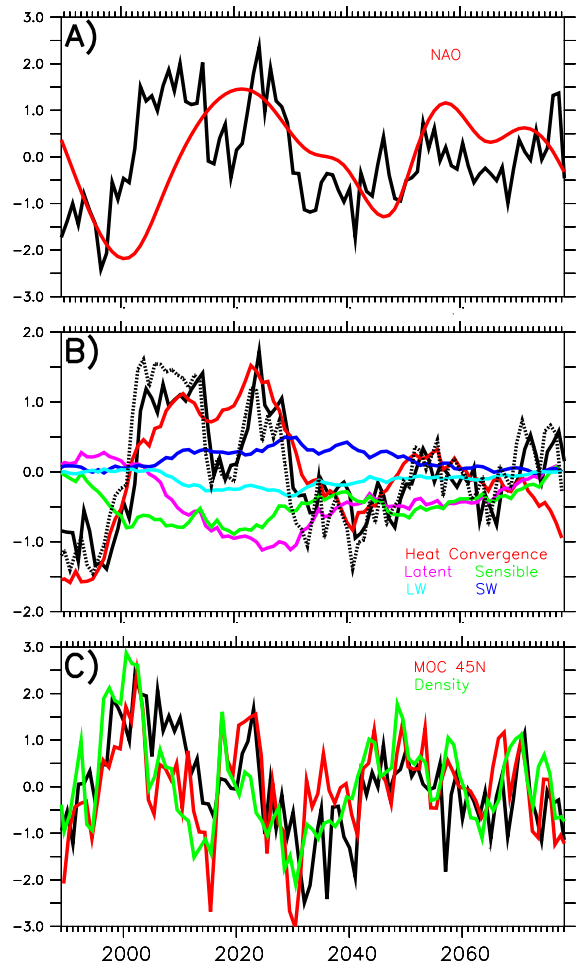

Fig. 13 Decadal NAO variability and Sub Polar Gyre heating in HiGEM Control simulation. A) Black: Mean Atlantic Sub Polar Gyre (SPG) Sea Surface Temperature (SST) $\left(75: 0^{\circ} \mathrm{W}, 45: 60^{\circ} \mathrm{N}-\right.$ box in Figure 12$)$. Red: Detrended decadal component of the NAO in HiGEM multiplied by -1 , extracted using EMD as for observations. Both indices have been standardized to have unit variance. B) Heat budget for the SPG region. Black solid: upper ocean heat content within the SPG region (0:500 m depth). Other lines - Heat content in the SPG due to: Ocean Heat convergence (Red), Surface Latent (Purple) and Sensible (Green) Heat fluxes and Longwave (Light Blue) and Shortwave (Dark Blue) surface radiation fluxes. All surface fluxes are defined positive into the ocean. Black dotted line: the sum of all contributions to the heat content. All indices have been detrended. Units are $10^{7} \mathrm{PJ}$. Black (solid and dotted) lines have been multipled by 2 to aid comparison with SPG SST in panel A. C) Black: Ocean Heat Convergence Flux into the SPG region $\left(45: 60^{\circ} \mathrm{N}\right)$. Red: Atlantic Meridional Overturing Circulation (AMOC) at $45^{\circ} \mathrm{N}$ (AMOC is the integral of southward meridional ocean velocity between 1000:7000 m across the Atlantic Basin). Green: Mean Ocean Density on the Deep western Atlantic Boundary (1500:3000 m 59:58 ${ }^{\circ} \mathrm{W} 44: 45^{\circ} \mathrm{N}$ ). All indices have been detrended and standardized to have unit variance. 


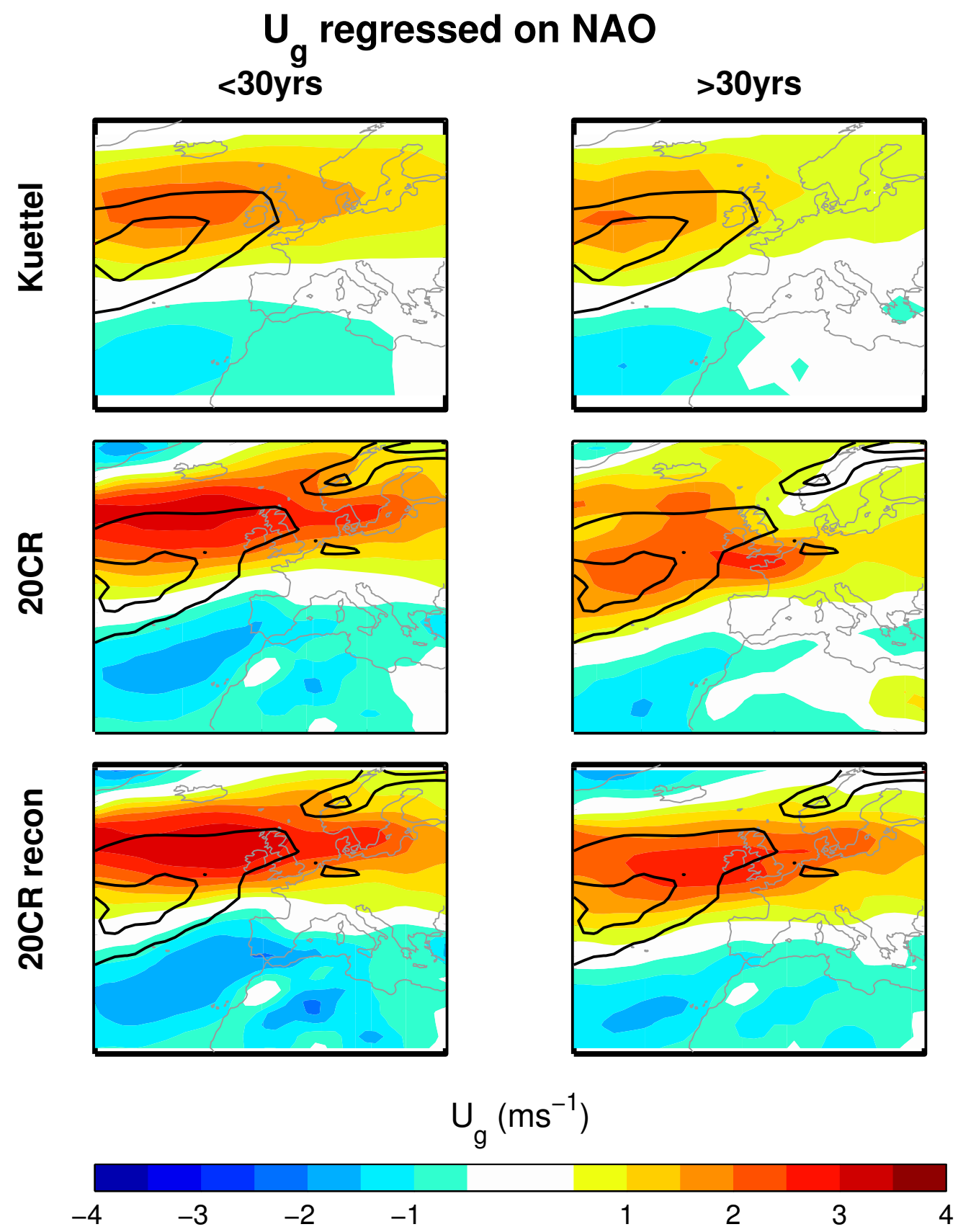

Fig. 14 As Figure 3 but showing the surface geostrophic zonal wind using the Küttel reconstruction and the $20 \mathrm{CR}$ data. The wind climatology is contoured in black at \pm 5 , $7 \mathrm{~ms}^{-1}$. The reconstruction only covers the region shown. See text for further details. 